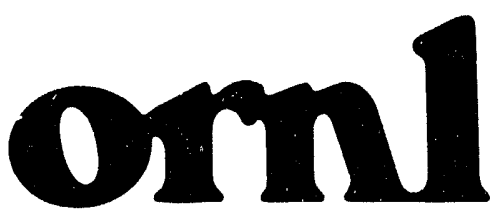

OAK RIDGE NATIONAL LABORATORY
MARTIN MARIETTA

\section{A Carbon-Carbon Composite \\ Materials Development Program for Fusion Energy Applications}

\author{
T. D. Burchell \\ W. P. Eatherly \\ G. B. Engle \\ G. W. Hollenberg
}


This report has been reproduced directly from the best available copy.

Available to DOE and DOE contractors from the Office of Scientific and Technical Information, P.O. Box 62, Oak Ridge, TN 37831; prices available from (615) 576-8401, FTS 626-8401.

Available to the public from the National Technical Information Service, U.S. Department of Commerce, 5285 Port Royal Rd., Springfield, VA 22161.

This report was prepared as an account of work sponsored by an agency of the United States Government. Neither the United States Government nor any agency thereof, nor any of their employees, makes any warranty, express or implied, or assumes any legal liability or responsibility for the accuracy, completeness, or usefulness of any information, apparatus, product, or process disclosed, or represents that its use would not infringe privately owned rights. Reference herein to any specific commercial product, process, or service by trade name, trademark, manufacturer, or otherwise, does not necessarily constitute or imply its endorsement, recommendation, or favoring by the United States Government or any agency thereof. The views and opinions of authors expressed herein do not necessarily state or reflect those of the United States Government or any agency thereof. 
Meials and Ceramics Division

\section{A CARBON-CARBON COMPOSITE MATERIALS DEVELOPMENT PROGRAM FOR FUSION ENERGY APPLICATIONS}

T. D. Burchell, W. P. Eatherly, G. B. Engle, and G. W. Hollenberg

Date Published: October 1992

NOTICE: This document contains information of a preliminary nature. It is subject to revision or correction and therefore does not represent a final report.

Prepared for the

DOE Office of Fusion Energy

AT $150401 \mathrm{E}$

Prepared by the

OAK RIDGE NATIONAL LABORTORY

Oak Ridge, Tennessee 37831-6285

managed by

MARTIN MARIETTA ENERGY SYSTEMS, INC.

for the

U.S. DEPARTMENT OF ENERGY

under contract DE-AC05-84OR21400 
CONTENTS

$\underline{\text { PAGE }}$

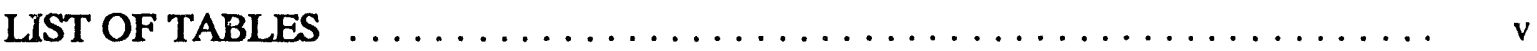

LIST OF FIGURES $\ldots \ldots \ldots \ldots \ldots \ldots \ldots \ldots \ldots \ldots \ldots \ldots \ldots \ldots \ldots \ldots$

LIST OF ACRONYMS $\ldots \ldots \ldots \ldots \ldots \ldots \ldots \ldots \ldots \ldots \ldots \ldots \ldots \ldots \ldots$

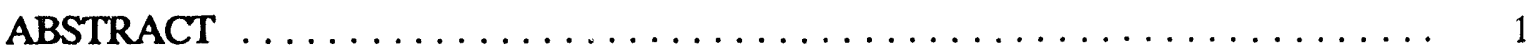

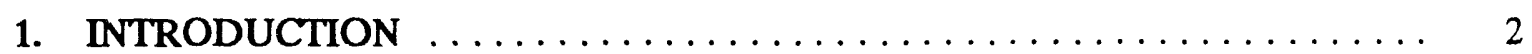

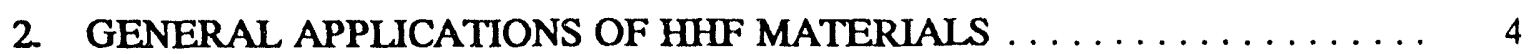

2.1 FUNCTIONAL REQUIREMENTS $\ldots \ldots \ldots \ldots \ldots \ldots \ldots \ldots \ldots \ldots$

2.2 OPERATIONAL REQUIREMENTS $\ldots \ldots \ldots \ldots \ldots \ldots \ldots \ldots \ldots$

2.3 COMPONENT REQUIREMENTS $\ldots \ldots \ldots \ldots \ldots \ldots \ldots \ldots \ldots$

3. ISSUES FOR CARBON-CARBON COMPOSITES $\ldots \ldots \ldots \ldots \ldots \ldots \ldots$

4. PROGRAM LOGIC-TECHNICAL APPROACH $\ldots \ldots \ldots \ldots \ldots \ldots \ldots \ldots$

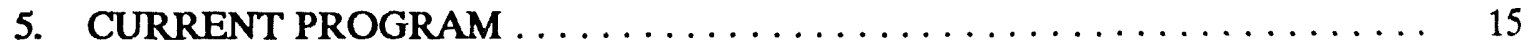

5.1 DEVELOPMENT OF NEW CARBON-CARBON MATERIALS . . . . . 15

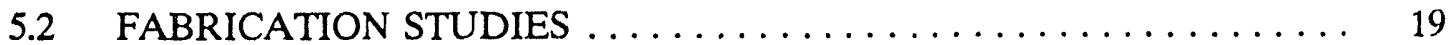

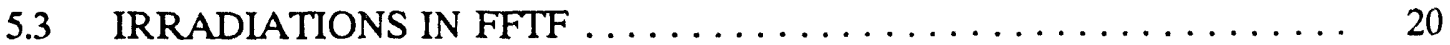

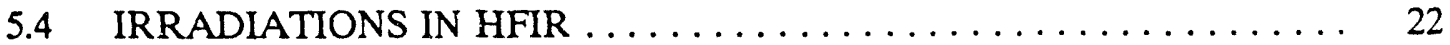

5.5 AN IRRADIATION-RESISTANT CARBON-CARBON COMPOSITE PFC MATERIALS CONCEPT $\ldots \ldots \ldots \ldots \ldots \ldots \ldots \ldots \ldots \ldots \ldots$

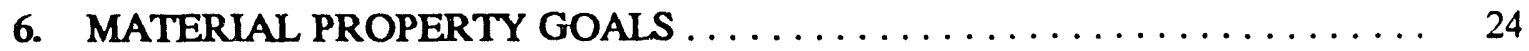

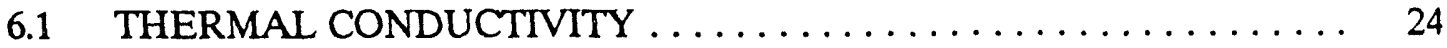

6.2 RADIATION-DAMAGE RESISTANCE ............... 25

6.3 DOPED MATERIALS FOR EROSION AND OXIDATION CONTROL 28

7. EUROPEAN AND JAPANESE FUSION CARBON-CARBON

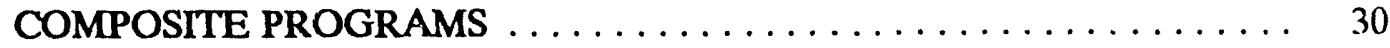

7.1 EUROPEAN TECHNOLOGY PROGRAMS .............. 30

7.2 THE JAPANESE PROGRAM $\ldots \ldots \ldots \ldots \ldots \ldots \ldots \ldots \ldots \ldots \ldots \ldots$

7.3 THE PROSPECTS FOR DEVELOPMENT OF CARBON-CARBON PFC MATERIALS OUTSIDE OF THE UNITED STATES . . . . . . 34

8. CARBON-CARBON COMPOSITE MATERIALS DEVELOPMENT COST AND SCHEDULE $\ldots \ldots \ldots \ldots \ldots \ldots \ldots \ldots \ldots \ldots \ldots \ldots \ldots \ldots \ldots \ldots$

9. CONCLUSIONS AND RECOMMENDATIONS $\ldots \ldots \ldots \ldots \ldots \ldots \ldots \ldots$

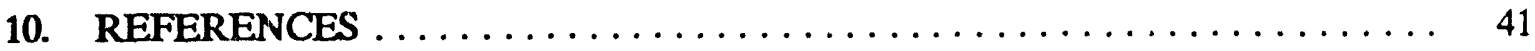

APPENDIX 1. CARBON-CARBON COMPOSITE WORKING GROUP (CCWG) CHARTER AND MEMBERS $\ldots \ldots \ldots \ldots \ldots \ldots \ldots \ldots \ldots \ldots \ldots$

APPENDIX 2 A REVIEW OF RADIATION DAMAGE DATA . . . . . . 45 


\section{LIST OF TABLES}

Table

$\underline{\text { Page }}$

1 Carbon-carbon composite development issues $\ldots \ldots \ldots \ldots \ldots \ldots \ldots \ldots$

2 HHF specimens in FFTF cycle 10 MOTA-1F $\ldots \ldots \ldots \ldots \ldots \ldots \ldots \ldots \ldots \ldots \ldots$

3 Materials included in the ORNL Program $\ldots \ldots \ldots \ldots \ldots \ldots \ldots \ldots$

4 Estimated thermal conductivities for a $2-D$ carbon-carbon $\ldots \ldots \ldots \ldots \ldots$ 2ó

5 European irradiation experiments involving graphites and carbon-carbon composite materials ................... 31

6 Carbon-carbon composite materials included in the JAERI

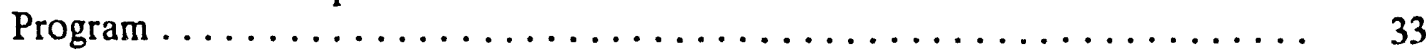

7 Mechanical and physical properties of the carbon-carbon composite materials in the JAERI evaluation program ............ 35

8 ORNL and materials costs associated with the development of carbon-carbon composite materials for ITER physics phase . . . . . . . . 39

A2.1 Mean equivalent diameter changes of irradiated fibers $\ldots \ldots \ldots \ldots \ldots \ldots .48$

A2.2 HHF specimens in FFTF cycle 10, MOTA-1F

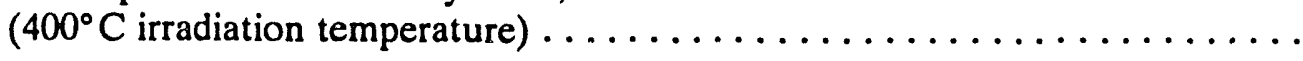




\section{LIST OF FIGURES}

Figure

Page

1 Components subject to $\mathrm{HHF}$ in a Tokamak $\ldots \ldots \ldots \ldots \ldots \ldots \ldots$

2 Carbon-carbon materials development $\ldots \ldots \ldots \ldots \ldots \ldots \ldots \ldots \ldots \ldots \ldots$

3 Sequence of design activities for a selected materiais concept .......... 14

4 Alternate diverter design concept (one piece) $\ldots \ldots \ldots \ldots \ldots \ldots \ldots \ldots$

5 The relationship between planned and ongoing graphite, carbon-carbon composite, and carbon fiber irradiations

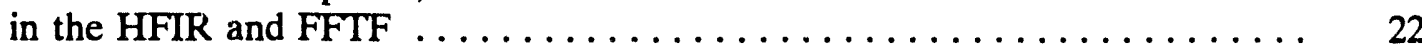

6 Neutron irradiation-induced volume changes in GraphNOL

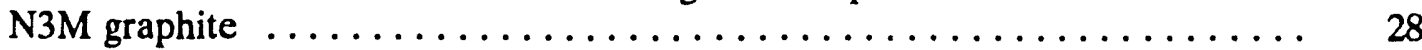

7 Comparison of ITER design schedule and carbon-carbon composite PFC materials development schedule .............. 37

A2.1 Radiation damage in graphites $\ldots \ldots \ldots \ldots \ldots \ldots \ldots \ldots \ldots \ldots \ldots \ldots$

A2.2 Radiation damage in carbon fibers $\ldots \ldots \ldots \ldots \ldots \ldots \ldots \ldots \ldots \ldots$

A2.3 Radiation damage in carbon fibers - fiber cracking $\ldots \ldots \ldots \ldots \ldots \ldots$

A2.4 Axial length changes of fibers in graphite and carbon cloths

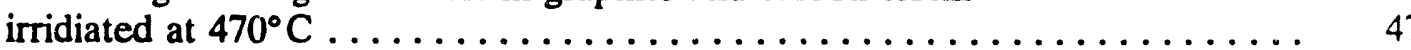

A2.5 The relationship between graphite crystallite size and c-axis growth rate $\ldots \ldots \ldots \ldots \ldots \ldots \ldots \ldots \ldots \ldots \ldots \ldots \ldots \ldots \ldots \ldots$

A2.6 Dependence of longitudinal shrinkage of carbon fibers on

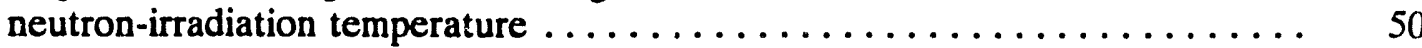

A2.7 Radiation damage in carbon-carbon composites $\ldots \ldots \ldots \ldots \ldots \ldots \ldots \ldots$ 


\section{ACRONYMS}

\begin{tabular}{ll} 
ATR & Advanced Test Reactor \\
BPNL & Battelle Pacific Northwest Laboratory \\
BPX & Burning Plasma Experiment \\
CCWG & Carbon-Carbon Composite Working Group \\
CTE & Coefficient of Thermal Expansion \\
CVD & Chemical Vapor Deposition \\
DPA & Displacement per Atom \\
EBR-II & Experimental Breeder Reactor II \\
FFTF & Fast Flux Test Facility \\
FMI & Fiber Materials, Incorporated \\
ITER & International Thermonuclear Experimental Reactor \\
HFIR & High Flux Isotope Reactor \\
HFR & High Flux Reactor \\
HHF & High Heat Flux \\
JAERI & Japan Atomic Energy Research Institute \\
JET & Joint European Torus \\
JMTR & Japan Material Test Reactor \\
KFA & Kernforschungsanlage GmbH, Jülich \\
MOTA & Materials Open Test Assembly \\
NAMCO & Nuclear and Aerospace Materials Corporation \\
ORNL & Oak Ridge National Laboratory \\
PAN & Poly-Acrylonitrile \\
PFC & Plasma-Facing Component \\
PMI & Plasma Materials Interactions \\
RFC & Random Fiber Composite \\
SEP & Societé Européene de Propulsion \\
TFTR & Tokomak Fusion Test Reactor \\
VGCF & Vapor-Grown Carbon Fiber \\
VGF & Vapor-Grown Fiber \\
\hline
\end{tabular}




\title{
A CARBON-CARBON COMPOSITE MATERIALS DEVELOPMENT PROGRAM FOR FUSION ENERGY APPLICATIONS*
}

\author{
Timothy D. Burchell, Walter P. Eatherly ${ }^{\dagger}$, \\ Glen B. Engle ${ }^{\ddagger}$, and Glen W. Hollenberg"
}

\begin{abstract}
Carbon-carbon composites increasingly are being used for plasma-facing component (PFC) applications in magnetic-confinement plasma-fusion devices. They offer substantial advantages such as enhanced physical and mechanical properties and superior thermal shock resistance compared to the previously favored bulk graphite. Next-generation plasma-fusion reactors, such as the International Thermonuclear Experimental Reactor (ITER) and the Burning Plasma Experiment (BPX), will require advanced carbon-carbon composites possessing extremely high thermal conductivity to manage the anticipated extreme thermal heat loads.

This report outlines a program that will facilitate the development of advanced carbon-carbon composites specifically tailored to meet the requirements of ITER and BPX. A strategy for developing the necessary associated design data base is described. Materials property needs, i.e., high thermal conductivity, radiation stability, tritium retention, etc., are assessed and prioritized through a systems analysis of the functional, operational, and component requirements for plasmafacing applications. The current Department of Energy (DOE) Office of Fusion Energy Program on carbon-carbon composites is summarized. Realistic property goals are set based upon our current understanding. The architectures of candidate PFC carbon-carbon composite materials are outlined, and architectural features considered desirable for maximum irradiation stability are described. The European and Japanese carbon-carbon composite development and irradiation programs are described.

The Working Group conclusions and recommendations are listed. It is recommended that developmental carbon-carbon composite materials from the commercial sector be procured via request for proposal/request for quotation (RFP/RFQ) as soon as possible.
\end{abstract}

"Research sponsored by the Office of Fusion Energy, U.S. Department of Energy, under contract DE-AC05-84OR21400 with Martin Marietta Energy Systems, Inc.

${ }^{+}$Consultant, Martin Marietta Energy Systerns, Inc., Oak Ridge Natl. Lab., Oak Ridge, Tenn.

INuclear and Aerospace Materials Corporation (NAMCO), Poway, Calif.

"Battelle Pacific Northwest Laboratory (BPNL), Richland, Wash. 


\section{INTRODUCTION}

Carbon-based materials are an attractive choice for fusion reactor plasma-facing components (PFCs) because of their low atomic number and superior thermal shock resistance. Early experimental tokamaks utilized graphite in their first-wall armor and plasma limiters. More recently, machines such as Princeton's Tokamak Fusion Test Reactor (TFTR) and Japan Atomic Energy Research Institute's (JAERI) JT-60, have switched from graphites to carbon-carbon composite PFCs because of their enhanced physical and mechanical properties and thermal shock resistance.

The next generation of tokamak machines, e.g., the International Thermonuclear Experimental Reactor (ITER) or the Burning Plasma Experiment (BPX), will place extreme demands on their PFCs, requiring materials with extremely high thermal conductivities, thermal shock resistance, and (eventually) neutron irradiation stability. Advanced carbon-carbon composites have the potential to satisfy many of the stringent demands anticipated for these new machines. Consequently, they have received increasing research interest from the High Heat Flux (HHF) and Plasma Materials Interactive (PMI) community in recent months. In order that these research and development (R\&D) activities might be coordinated and a coherent research

program leading to the development of carbon-carbon composite PFC materials identified, a carbon-carbon composite materials working group (CCWG) was established.

The CCWG was initiated at the request of M. Cohen of the Department of Energy (DOE), Office of Fusion Energy, in October 1989, under the chairmanship of T. D. Burchell. The working group's purpose and goals were defined in its charter as, "To define an integrated program of research sufficient to provide an engineering design data base for irradiated carbon materials relevant to the U.S. Fusion Energy Program, and to detail a strategy for the development within the United States of a high thermal conductivity, three-dimensional (3-D), carbon-carbon composite material suitable for first-wall applications in ITER and BPX." Details of the group's membership are in Appendix 1. At its first meeting on March 29, 1990, all aspects of the U.S. fusion energy carbon-carbon composite PFCs program were reviewed and discussed. At a subsequent meeting, a small nucleus of CCWG members agreed upon the outline and format of this document.

General applications of HHF materials in tokamaks are described here. Functional, operational, and component requirements for PFCs are defined. Two major functional requirements are identified: (1) to protect the structural and other components from plasma 
effects and (2) to protect the plasma from interaction with structural components that might degrade the plasma integrity. Operational requirements for HHF materials are that they should not: (1) compromise safety or environmental aspects of the plant, (2) cause unacceptable costs and operating schedules for the plant, or (3) interfere with the operation of other requirements. Nine separate component requirements are identified and detailed for carbon-carbon composites as HHF materials in Sect. 2.3 .

The issues for carbon-carbon composites as PFC and HHF materials are reported and discussed in Sect. 3. Of primary concern are irradiation dimensional stability, thermal conductivity (both initial and after degradation by neutron irradiation), and erosion. Secondary concerns are considered to be tritium retention, oxidation, maintenance, degassing, and the inadequacy of the data base for candidate carbon-carbon composite materials. Finally, four low-level issues are identified: thermal shock, plasma contamination, mechanical properties, and fabrication scale-up.

A logical technical approach for an integrated carbon-carbon composite PFC/HHF materials program is discussed in Sect. 4. A three-level approach is identified involving participation by DOE laboratories, universities, and vendors. Materials testing and performance evaluation would provide feedback for the optimization of the composite material to meet the previously stated requirements.

The current DOE carbon-carbon composite $\mathrm{PFC} / \mathrm{HHF}$ materials program is reviewed in Sect. 5. The potential for development of new carbon-carbon composite PFC/HHF materials is discussed. Candidate composite materials architectures are postulated for diverter and limiter applications in devices such as ITER and BPX. Two fabrication studies being performed for DOE under the Small Business Innovative Research (SBIR) Program [Nuclear and Aerospace Materials Corporation (NAMCO) and Applied Sciences] are described. Irradiation programs are currently in place at the Fast Flux Test Facility (FFTF) at Hanford and the High Flux Isotope Reactor (HFIR) at Oak Ridge National Laboratory (ORNL). Both programs are reported, and details of the temperature and fluence ranges covered by the experiments are provided. Existing irradiation damage and dimensional change data for carbon fibers and carbon-carbon composites are reported and reviewed. Materials models are postulated to explain the observed behavior.

The ca-bon-carbon composite PFC materials properties goals are reviewed in Sect. 6. Thermal conductivity is predicted for a range of two-dimensional (2-D) material based upon fiber and matrix properties. Radiation-damage resistance is discussed, and it is concluded that carbon-carbon composites may attain radiation lifetimes exceeding those achieved by bulk graphites. The benefits of boron and silicon additions are considered, and use of boron additions to accelerate irradiation studies is discussed. 
The Japanese and European PFC/HHF materials irradiation programs are summarized in Sect. 7. Concerns regarding the ability of our ITER partners to develop carbon-carbon compsite $\mathrm{PFC} / \mathrm{HHF}$ materials are highlighted. In Sect. 8, the cost of a carbon-carbon composite PFC materials development program is presented, and the program schedule is tied to the ITER engineering design activity timetable. Finally, the CCWG's conclusions and recommendations are reported regarding the future direction of the carbon-carbon composite $\mathrm{PFC} / \mathrm{HHF}$ materials development/irradiation program.

\section{GENERAL APPLICATIONS OF HHF MATERIALS}

Figure 1 is a schematic cross section of the magnetically confined fusion reactor, which highlights the three primary PFCs: the first wall, the diverter, and the limiter.

ORNL-DWG 92-5119

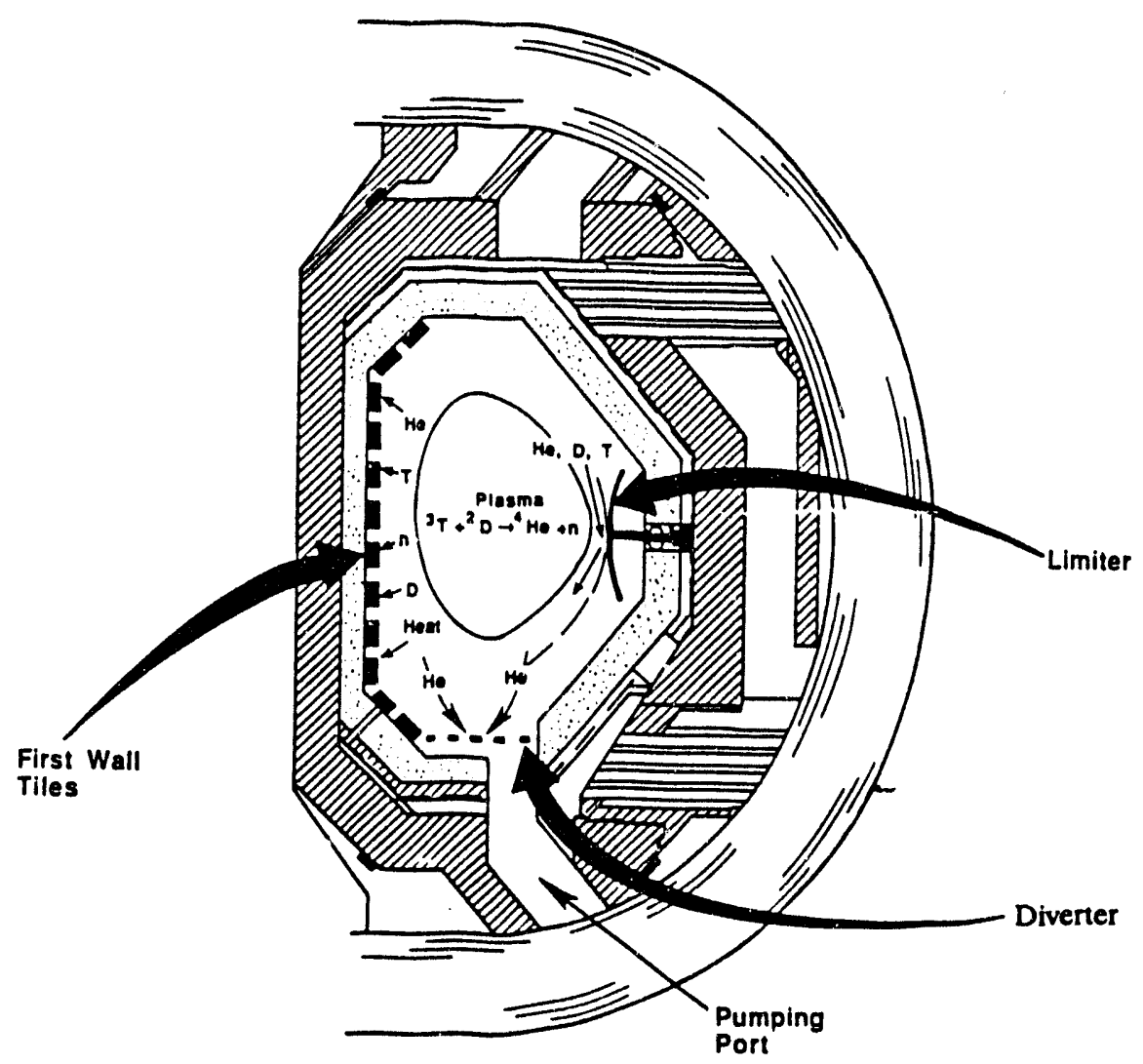

Fig. 1. Components subject to HHF in a Tokamak. 
1. The first wall, although the largest of these components, receives the lowest heat flux $\left(<10 \mathrm{MW} / \mathrm{m}^{2}\right.$ ) except for localized heating during disruptive accidents. The present requirements of the plasma-facing materials in the first wall do not include the ability to withstand plasma disruption accidents. The first wall is strategically located between the plasma and the structural material that forms the vacuum vessel of the plasma chambei: Cooling channels are typically provided in or on the structural material.

2. The limiter or limiters are located near the centerline of the torus on the outside wall. The purpose of the limiter is to "shape" the plasma and "limit" the size of the plasma within the vacuum vessel. Limiters can be fixed or movable; the latter provide greater flexibility in modifying the plasma characteristics.

3. The diverter is located at the bottom and/or top of the plasma chamher. The purpose of the diverter is to shield the port into which ions in the plasma are electromagnetically directed so that plasma composition and vacuum characteristics can be maintained.

Because limiters and diverter plates intentionally interact with the plasma, they receive higher heat loads $\left(>10 \mathrm{MW} / \mathrm{m}^{2}\right)$ than the first wall. The impinging heat load on all these components is due to several types of emitted energy: photons, electrons, neutrons, ions, etc. Each of these possesses its own characteristics as far as depth of penetration, heat load, and damage to the HHF material are concerned. Neutrons, for example, can penetrate materials and deposit only a fraction of their energy, but they cause microstructural damage throughout the material. Ions, on the other hand, deposit essentially all of their energy near the surface of the HHF material leaving the underlying material unscathed. Obviously, the specific environmental parameters that the HHF materials must survive vary considerably between devices and their applications within those devices (limiter, diverter, and first wall). The general requirements, however, remain the same in all the devices; only the severity of the environment to which they are exposed changes.

The following analyses of functional, operational, and component requirements are based upon the approach outlined in DOE Order No. 4700.1, entitled "Project Management Systems," by the Office of Projects and Facilities Management (March 6, 1987). 


\section{FUNCTIONAL REQUIREMENTS}

The primary functional requirements, i.e., first-level functional requirements, for all of the applications of HHF materials can be condensed into the following requisites:

1. Shall protect the structural and other components from plasma effects. The HHFs imposed upon the limiter and diverter require that the underlying structural alloys, such as stainless or territic steels, be protected. The already stringent requirements on the structural materials. i.e., dimensional stability, structural strength, vacuum containment, etc., bave led designers to corwider a multilayer approach. Such an approach disassociates the tunctional requirements of the HHF material from those of the structural material. Hence, the HHF materials have reduced requirements associated with load bearing, dimensional stability, etc., and primarily must protect the underlying structural materials.

2 Shall protect the plasma from degradation by interactions with the plasma-facing materials. Plasma physios requires that energy-degrading impurity nuclei be excluded to achieve optimum plasma conditions. Low-Z elements such as carbon are less degrading than high- $Z$ elements such as tungsten. However, if a sufficient mass of low-atomic-number material is vaporized, the plasma can still be detrimentally affected. Chemical interactions between the PFCs and the plasma should also be avoided for the same reason.

\section{OPERATIONAL REQUIREMENTS}

The operational requirements of HHF materials include the following requisites:

1. Shall not compromise safety or environmental aspects of the entire plant. The general safety of the plant should not be compromised by the introduction of the HHF material. Compromising safety and environmental aspects of the plant must be viewed in a very global context, including even fire, explosion, toxic and radioactive exposure, toxic and radioactivity emission, etc.

2. Shall not lead to unacceptable costs and schedules of the entire plant.

a. Schedule. For fusion energy programs (e.g., ITER development), schedules typically are charted over a decade or more. The development of HHF materials must be bounded by realistic schedules. For example, PFC development for ITER requires that materials be available with established technology during the last half of this decade. Although it may well be easier to develop materials for the unique and more limited criteria associated 
with ITER, than the more challenging criteria associated with full-scale fusion power plants, it is more cost effective to evolve these materials in a parallel path with the machines. Cost and schedule are typically inseparable, with highly accelerated or protracted schedules both yielding excessive costs.

b. Initial cost, including developmental costs. The initial development costs are presently bounded by limited budgets in the fusion HHF materials arena. Even with international cooperation on fusion energy, the challenges facing the HHF materials area necessitate that the materials be selected in a cost-effective manner. Consequently, large materials development programs appear to be inappropriate; rather, the approach should be limited to the development of materials using existing technology to obtain improved performance, i.e., modification of existing carbon-carbon fabrication techniques.

c. Lifetime. Lifetime must be viewed directly as a cost item for the HHF materials. Lifetime of the first wall may be required to be equal to the structural material immediately behind it unless remote techniques for removal and installation are developed. Lifetime of the diverters and limiters can be considerably shorter than that of the first wall, since these components may be replaced during shutdowns. Exposures of 100 displacements per atom (dpa) for an HHF material at the full lifetimes of power plants are not readily achievable by any present material. Exposures of 1 to 20 dpa encountered in near-term devices appear to be a more realistic goal with present funding.

d. Replacement or repair. Replacement or repair of the HHF material in place is a requirement that parallels the concept of lifetime. If lifetime is limited, then the repair of the existing HHF material or its replacement is a necessary requirement.

3. Shall not interfere with the operation of other components. The PFC material must not interfere with the operation of other critical systems, i.e., diagnostic, energy input, magnet, vacuum, etc., necessary to the operation of the fusion device.

\section{COMPONENT REQUIREMENTS}

The generalized functional and operational requirements can be distilled down into more focused component requirements only when a specific material and concept are examined. For carbon-carbon composite tiles used as HHF material in a fusion power plant, the following list 
of component requirements can be generated based upon the concept of maintaining functional integrity:

1. high thermal-shock resistance;

2. acceptable irradiation-induced property changes (dimensional and thermal conductivity);

3. minimal tritium retention;

4. low chemical, physical, or radiation-enhanced erosion rates;

5. tailorable thermal conductivity;

6. low outgassing;

7. resistance to steam oxidation;

8. fabricable into engineering components; and

9. maintainability.

\subsubsection{Thermal-Shock Resistance}

The thermal-shock-resistance requirement is tied directly to the ability of the HHF material to remain in position and thus separate the plasma and the structural materials. Carbon-carbon composites were originally developed for the purpose of surviving thermal shock; hence, the thermal-shock-resistance requirement is not by itself challenging for this material.

\subsection{Irradiation-Induced Property Changes}

Acceptable irradiation-induced property changes are primarily focused on dimensional stability and thermal conductivity, although other properties such as thermal expansion, emissivity, erosion, etc., are also important. The dimensional stability of the carbon-carbon composites is required from a gross sense to ensure that intimate contact (i.e., high thermal transport) can be maintained with the dimensionally stable structural material below it. In addition, the size and location of the carbon-carbon surface determine specifically the amount of interaction that it has with the plasma. A small displacement of the carbon-carbon surface in the limiters or first wall can cause extreme variations in heat deposition rates. Irradiation by neutrons typically degrades the thermal conductivity of solids by the introduction of voids, bubbles, cavities, interstitials, and other defects. A reduced thermal conductivity directly leads to higher surface temperatures of the composite, which tends to reduce its capacity to satisfy erosion and oxidation requirements.

\subsubsection{Tritium Retention}

Tritium retention is primarily important because of the generation of an inventory which potentially could be dispersed at a later event into the plant containment or the environment. Carbon-carbon composites are porous as a consequence of their fabrication methodology, be it 
either chemical vapor deposition (CVD) or impregnation and pyrolysis. Hence, composites possess large specific surface areas and, at moderate temperatures, the ability to retain hydrogen in either the form of protium, deuterium, or tritium.

\subsubsection{Erosion}

Erosion of the carbon-carbon composite may determine the lifetime of a component and hence has a criticai impact on the cost of operation and maintenance of a fusion device. In addition, the eroded material is injected into the plasma and contaminates it. Finally, the eroded material is redeposited in other areas of the plasma chamber in a manner that may negatively impact other components.

\subsubsection{Thermal Conductivity}

Thermal conductivity directly affects the temperature gradient across the composite during operation and thus the surface temperature of the composite. The thermal conductivity of graphite fibers can be more than an order of magnitude higher in the axial direction than in the radial direction. Consequently, conductivity in the composite is primarily along the fiber directions, and the composite conductivity is a reflection of the fiber density in a particular direction. The conductivity along the fibers can be as high as $1,180 \mathrm{~W} /(\mathrm{m} \cdot \mathrm{K})$, which approaches that of graphite single crystals $[2,600 \mathrm{~W} /(\mathrm{m} \cdot \mathrm{K})]$.

\subsection{Outgassing}

Outgassing is important because high outgassing rates can impede the initial startup of the device. It is envisioned that conventional construction techniques will be used to fabricate the large torus structures. During construction, moisture and other gases will be absorbed onto the surfaces of the composites. Removal of these gases is necessary in order to obtain a vacuum sufficient to achieve plasma conditions.

\subsection{Steam Oxidation}

Oxidation of the composites by steam or air is not considered to be a problem during normal operating conditions; however, during an accident in which these gases gain entry into the plasma chamber, the composite will be the hottest solid material in the chamber. The oxidation of the composite at this point should be limited and controllable.

\subsection{Fabricability}

The fabrication of carbon-carbon composites into the shapes and sizes required to line the first wall, limiters, and diverters is an obvious necessity. Composites can be readily formed into 
limited thicknesses using a variety of techniques. The thickness limitation is typically associated with diffusion of pyrolysis gases in or out of the material. The overall dimensions of the composite are limited by furnace size and perhaps weaving capacity. Since the preform of woven fibers (without the matrix) can be easily reformed, it is possible to achieve net-shape forming for the contours defined by the fusion torus. Because the yarn (fiber bundle) used in most commercial composites contains thousands of individual filaments, as-fabricated surface roughness may not be smooth enough to allow adequate heat transfer to the coolant tubes.

\subsubsection{Maintainability}

Maintainability iacludes the ability to replace or repair carbon-carbon composites that may be damaged during operation. If limiters and diverters are completely removable, they can be replaced or refurbished. The first wall is much less accessible but fortunately has a much lower imposed erosion rate.

\section{ISSUES FOR CARBON-CARBON COMPOSITES}

Carbon-carbon composites remain candidates for HHF applications because they possess: (1) high thermal shock resistance, (2) low plasma contamination, (3) good mechanical properties,

(4) high thermal conductivity, (5) good operational experience, and, moreover, (6) the material can be tailored to meet specific component property requirements.

For future development of carbon-carbon composites, the issues must be clearly defined and prioritized. In this context, issues arise when current materials are unable to satisfy component design requirements. The discussion is purposefully nonspecific so that it may be relevant to the long period of time in which fusion devices will evolve. Composite development issues are listed in Table 1 and are prioritized into three general areas.

Primary basis issues associated with the functional requirements are irradiation stability, thermal conductivity, and erosion. While secondary issues are considered important, they are chronologically secondary and should be evaluated after success has been achieved in the primary area. Finally, the tertiary (low-level) issues are listed, which are not considered major concerns at this time.

Irradiation of a variety of commercial carbon-carbon composites in the FFTF Materials Open Test Facility (MOTA) has demonstrated a wide range of dimensional stability. Some composites exhibited essentially no dimensional change while others swelled as much as $84 \%$ in 
Table 1. Carbon-carbon composite development issues

\begin{tabular}{lll}
\hline Primary issues & Secondary issues & Tertiary (low-level) issues \\
\hline $\begin{array}{l}\text { Irradiation dimensional } \\
\text { stability }\end{array}$ & Tritium retention & Thermal shock \\
$\begin{array}{l}\text { Thermal conductivity } \\
\begin{array}{l}\text { 1. Initial conductivity } \\
\text { of composite parallel with } \\
\text { the heat flux }\end{array}\end{array}$ & Oxidation & Plasma contamination \\
$\begin{array}{l}\text { 2. Degradation due to } \\
\text { irradiation }\end{array}$ & Maintenance & \\
\hline
\end{tabular}

one direction (see Appendix 2). None of the composite materials possessed low-dimensional changes in all directions. This emphasizes the need to specifically tailor the composites for swelling resistance.

Extremely high thermal conductivity is required for PFCs of ITER and BPX. Details of these requirements and an approach to achieving high-conductivity composites based upon fiber selection, weaving, and processing will be presented in Sect. 5 .

Erosion resistance remains a primary life-limiting issue; therefore, it must be addressed through materials modifications and development. High-density and highly oriented materials would appear to possess better resistance to erosion.

Tritium retention, oxidation, and degassing are important to the operational requirements, including safety, but do not affect the functional requirements defined in Sect. 2.1. The limited data base on carbon-carbon composites is an issue but must be addressed after suitable materials have been developed.

Thermal shock, plasma contamination, mechanical properties, and fabrication are low-level issues because of the inherent superior performance of carbon-carbon composites over other materials.

\section{PROGRAM LOGIC-TECHNICAL APPROACH}

In Fig. 2, the logic diagram for the technical approach is presented. Three different sources of information are used to develop the material concept for the tailoring of advanced composites suitable for use as fusion HHF materials. 
ORNL-DWG 92-5120

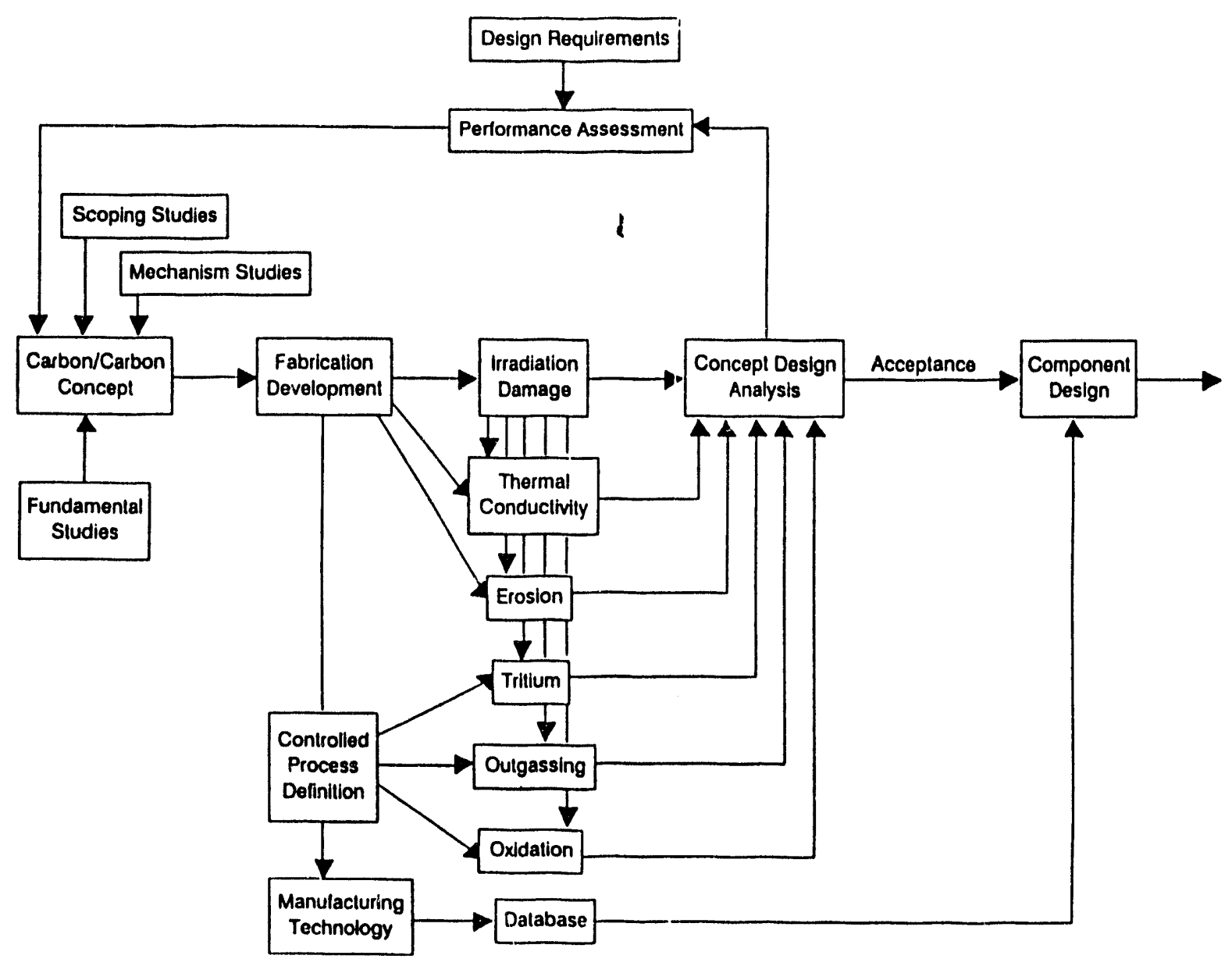

Fig. 2. Carbon-carbon materials development.

First, the scoping studies previously conducted in either FFTF or HFIR on commercially available composites, when available, will be used to formulate correlations and theories of microstructural effects on dimensional changes and thermal conductivity.

Secondly, fundamental studies will form the basis for extrapolation of effects to new materials and environments. Data on fibers are critical to understanding the composites' overall behavior. After further analysis of scoping studies, other efforts will be defined that can be undertaken at universities and other appropriate institutions to deal with fundamental studies. Possible areas for fundamental studies are weaving effects on dimensional changes and thermal conductivity and fiber/matrix interactions during heat treatment and irradiation, but fiber studies form the basis for all this work. 
Thirdly, fabrication studies and insight by vendors must be included to ensure that the composite concepts developed are practical and fabricable. For example, limitations are imposed on the tightness of weaving by the use of high-modulus fibers.

The carbon-carbon composite materials concepts are trade-offs among the types of weaving, fibers, matrix material, architecture, and processing that will provide the properties necessary to satisfy the requirements previously described. The evolution of an optimum material concept will require the integration of the views and ideas of experts in fusion energy and carbon-carbon fields. Fabrication, unirradiated and irradiated properties data, and engineering performance predictions will provide further guidance to the development of an optimum material concept.

After a material concept is accepted, projected properties will be compared against engineering performance requirements. If the hypothesized properties are adequate, fabrication studies will be conducted in the commercial sector. The material fabricated will then be subjected to properties screening tests based upon the primary issues:

1. thermal conductivity - unirradiated,

2. dimensional stability - irradiated,

3. thermal conductivity - irradiated, and

4. erosion testing.

As this testing is completed, the results will be fed to design analysis where the material concept will be compared with existing materials. This design analysis must take on both the aspects of near-term and full-power-plant HHF applications. In addition, the PFC materials applications must be considered. For example, a material with high-irradiation stability is necessary for first wall, but intermediate stability could be tolerated for a more erosion-resistant material in a limiter application.

In the engineering performance area, the overall behavior of the material concept will be evaluated by considering the design analysis under a variety of conditions. If further materials development is considered cost effective, new materials concepts must be initiated and the entire process of fabrication, unirradiated properties, irradiated properties, etc., iterated. If the present materials concept is adequate, then secondary issues will be evaluated, such as tritium retention, oxidation, degassing, etc.

Materials will be supplied to existing devices, such as the Tokomak Fusion Test Reactor (IFTR) and Doublet III, for evaluation of plasma interactive effects. Performance data shall be reviewed by the CCWG. Analyses of such data may lead to further improvement of the materials concept. 
Based on the foregoing discussion, a three-stage materials development program leading to prototypical carbon-carbon composite PFCs is outlined in Fig. 3, where the four major decision points identified are:

1. selection of a specific materials concept,

2. performance assessment of the concept material,

3. preliminary component design evaluation, and

4. final design assessment.

ORNL-DWG 92-5121

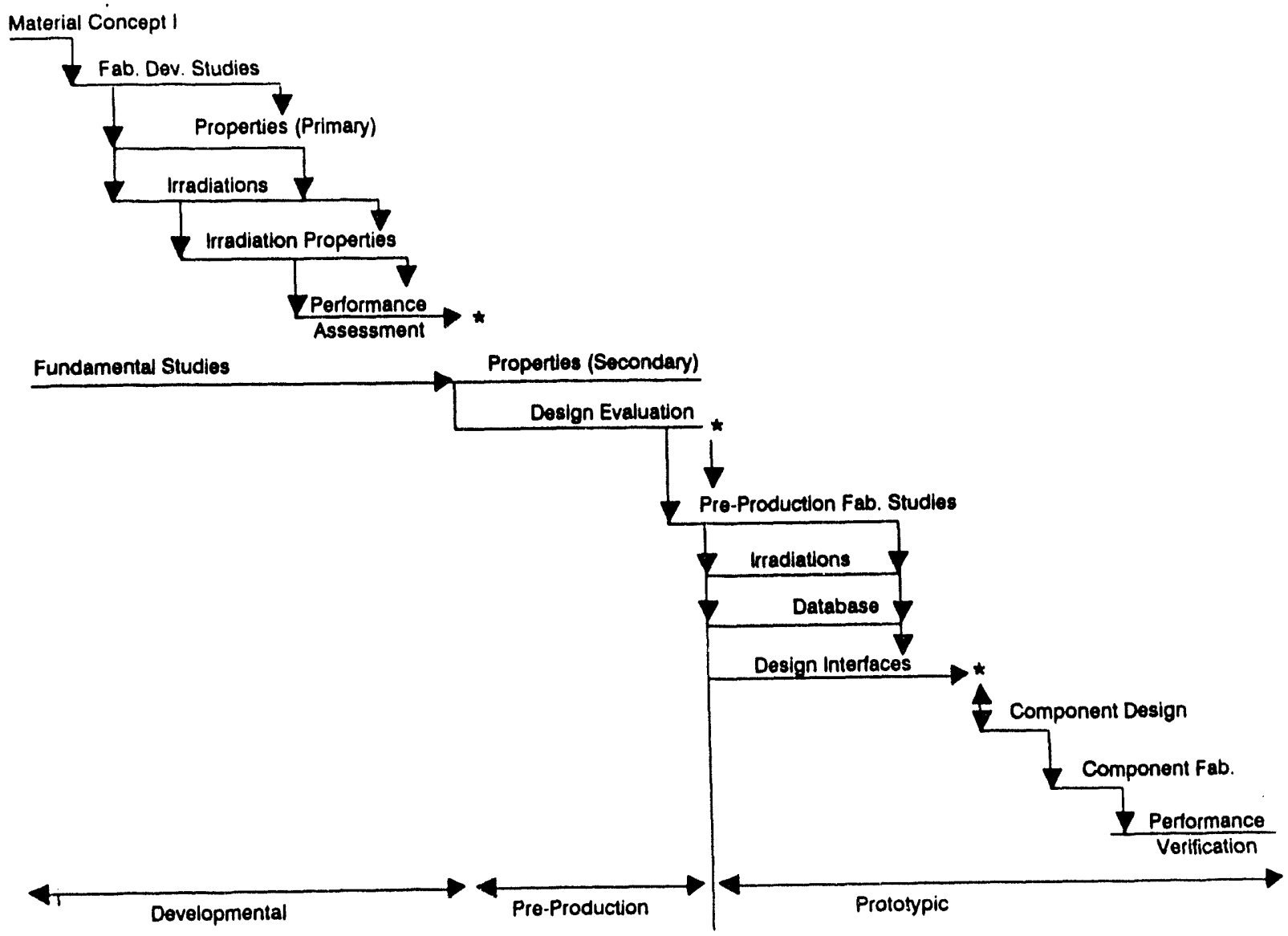

Inticates major docision poirt

Fig. 3. Sequence of design activities for a selected materials concept. 


\section{CURRENT PROGRAM}

\subsection{DEVELOPMENT OF NEW CARBON-CARBON MATERIALS}

Composite materials are designed to meet specific applications, and it is therefore unlikely that suitable carbon-carbon composite materials already exist for the diverter and limiter designs required in the ITER and BPX. However, recent advances in the field of carbon fiber technology, particularly the development of very-high-modulus, high-thermal-conductivity fibers based on mesophase pitches, make the prospects for development of suitable carbon-based composite materials excellent.

\subsubsection{Design Property Requirements}

Functional, operational, and component requirements were described in detail in Sect. 2. Here, particular design property requirements are discussed and carbon-carbon composite materials design solutions postulated.

\subsubsection{Thermal Conductivity}

Thermal conductivity is one of the most stringent property requirements for the limiters and diverters of ITER and BPX. Recently, thermal conductivity requirements for the BPX's PCFs were published. ${ }^{1}$ The limiter requires a room-temperature thermal conductivity in excess of $200 \mathrm{~W} /(\mathrm{m} \cdot \mathrm{K})$, and the diverter requires a thermal conductivity greater than $600 \mathrm{~W} /(\mathrm{n} \cdot \mathrm{K})$, both in the direction normal to the plasma-facing surface. The limiter thermal conductivity will most likely be achieved by utilizing high-conductivity pitch fibers in this direction. However, the very-high-conductivity requirement of the diverter poses a significant challenge for carbon-carbon composite materials. The solution for the diverter may be found through innovative composite materials concepts such as those being funded under the DOE's SBIR Program (see Sect. 5.2).

The current diverter concept for BPX involves the use of pyrolytic graphite tiles, either brazed or mechanically attached to a support structure. The ITER diverter is actively cooled and will use carbon-carbon composite tiles aligned with the direction of maximum thermal conductivity perpendicular to the plasma surface. For BPX, the maximum thickness of the tile is limited by the manufacturing process to a few millimeters. In BPX and ITER, a large number of tiles and an extremely reliable braze technique will be required. The development of an all-carbon-carbon composite diverter armor tile, fabricable in large sections, may be essential for the diverters of future plasma fusion devices. 


\subsubsection{Electrical Resistivity}

A secondary materials property consideration for PFCs is electrical resistivity in the in-plane $(x-y)$ direction. During plasma disruptions, the eddy currents induced in the component skin create forces through reaction with the magnetic confinement field. These forces are reduced if the electrical resistivity in the $x-y$ plane can be increased. For the BPX, the recommended minimum resistivity for the diverter and limiter were reported ${ }^{1}$ as 0.003 and 0.00015 $\mu \Omega \cdot m$, respectively.

\subsubsection{Thermal Stresses}

Temperature gradients that will develop in PFCs give rise to thermal stresses. To minimize these, the coefficient of thermal expansion (CTE) should be small. For BPX limiters, the maximum CTE has been set at $1 \times 10^{-6} /{ }^{\circ} \mathrm{C}$. Moreover, excessive bowing of the panels during operation would allow the front surface to interfere with the plasma. Consequently, adequate stiffess must be designed into the panel. For a BPX panel, the minimum Young's modulus is $55 \mathrm{GPa}$. Fortuitously, the CTE is generally lower in the high-modulus (stiffest) carbon fibers.

To resist internal stresses generated by the combined effect of temperature gradient and disruption bads, a carbon-carbon composite limiter must, in general, also possess adequate compressive, flexural, and shear strengths. The latter two of these properties can be met with reasonable confidence. However, carbon-carbon composites do not generally behave well under compressive stress. This problem is compounded with the trend for lower fiber strength to be coupled with higher modulus and degree of crystallinity. These high-modulus fibers are precisely the ones that are desirable if CTE is to be reduced in the $x-y$ plane. Furthermore, it should be remembered that electrical resistivity will decrease with increased fiber crystallinity. Evidently, the selection of fiber type in the $x-y$ directions of the carbon-carbon PFC material will be a compromise between the design requirement and fiber electrical resistivity, CTE, strength, and elastic modulus. To better illustrate these considerations, plausible choices of appropriate fibers/architectures are discussed in detail in Sects. 5.1.2 and 5.1.3.

\subsubsection{A Carbon-Carbon Composite Limiter or First Wall}

In conventional, orthogonal, 3-D, carbon-carbon composite material, the maximum fiber content will be approximately $45 \%$. In a BPX limiter, the overriding concern is to achieve 
the desired through-thickness (z-direction) thermal conductivity. Consequently, the fraction and thermal conductivity of the $z$-direction fibers should be maximized. The following fiber choices are proposed:

1. $x$ and $y-15 \%$ Poly-acrylonitrile (PAIN) or pitch, and

2. $z-3 n \%$ pitch fiber.

The composite should be densified through a combination of CVD and/or repetitive pitch impregnations to a value of approximately $1.9 \mathrm{~g} / \mathrm{cc}$. (Higher densities will decrease the thermal shock resistance of the composite.) The stresses on the limiter will be reduced if the thermal gradient through the thickness can be reduced. This can be achieved by selecting high-modulus mesophase-pitch fibers with conductivities $>1000 \mathrm{~W} /(\mathrm{m} \cdot \mathrm{K})$ in the $\mathrm{z}$ direction.

\subsubsection{A Carbon-Carbon Composite Diverter}

It will be necessary to maximize both the fiber fraction and conductivity in the $z$ direction to achieve the very-high-radial thermal conductivity needed for this component. Therefore, high-modulus mesophase-pitch fiber with the highest thermal conductivity should be specified in the $\mathrm{z}$ direction. The carbon-carbon composite diverter design proposed as an alternate for the BPX has no $x$-y fibers in the inner (plasma-facing) skin (see Fig. 4). Consequently, the electrical resistivity will be large in directions parallel to the limiter's surface. This is attributable to the anisotropy of graphitic crystals for which the c-axis resistivity is 1 to $10 \Omega \mathrm{m}$. For a unidirectional composite, this would translate to a ten-fold or more increase in electrical resistivity. Consequently, the choice of $x-y$ fibers will, to a large degree, be governed by the mechanical properties required. Reinforcement of critical load-bearing areas, such as attachment lugs, may be possible by locally increasing the $x-y$ fiber content at the expense of the $z$ direction. Difficulties in selecting the $x-y$ fibers stem from a desire to maximize strength. High-strength fibers tend to possess lower moduli, which is desirable. However, since the higher-modulus fibers generally exhibit lower CTEs, the final selection must be a compromise.

The following fibers and architecture are suggested:

1. $x, y$ - Backing - $20 \%$ PAN or pitch fibers

Face $-0 \%$

2. $z$ - Backing - $25 \%$ high-conductivity pitch fibers

Face - $60 \%$ high-conductivity pitch fibers

(localized unidirectional) 
ORNL-DWG 92-5122

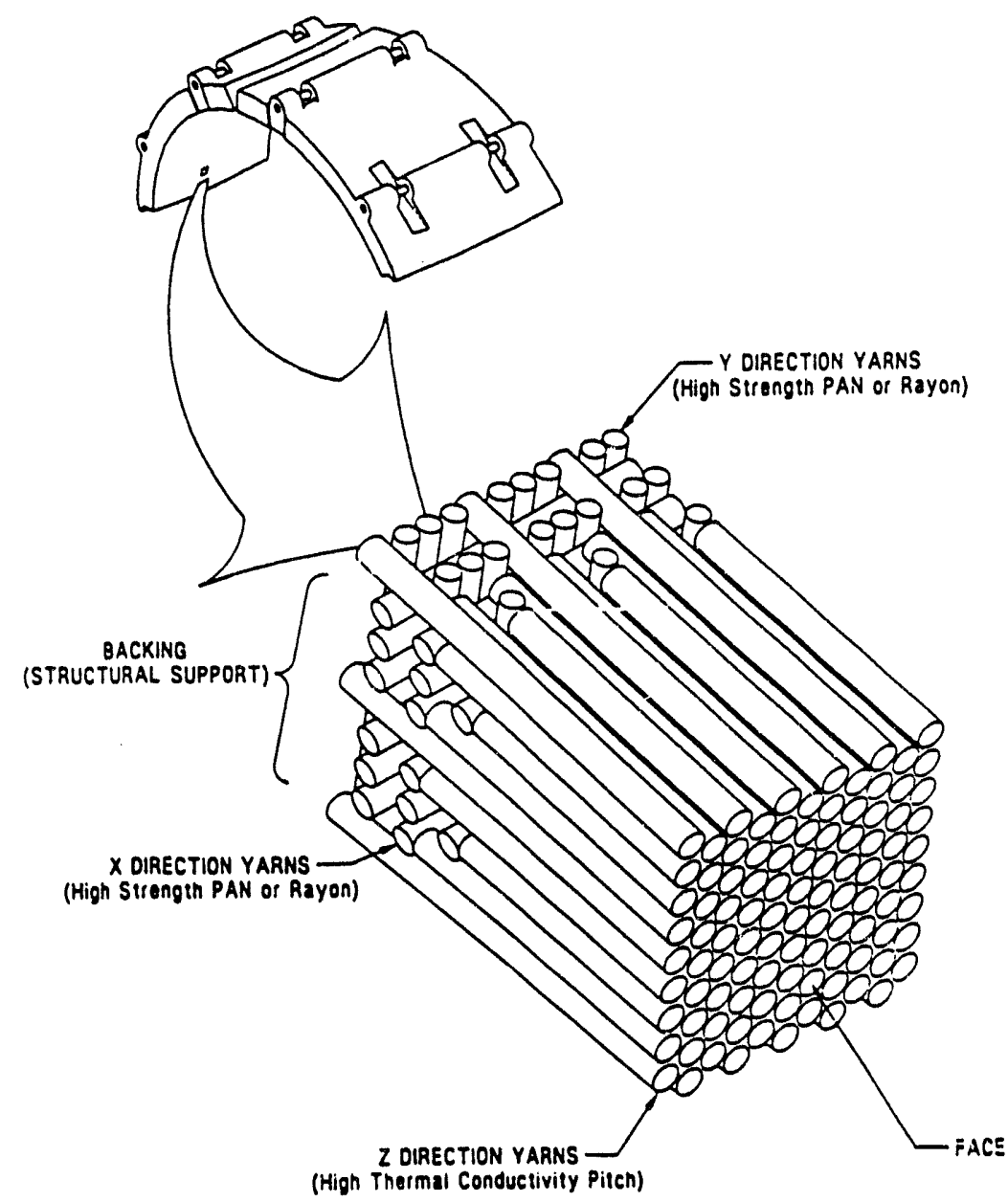

Fig. 4. Alternate diverter design concept (one piece). See Sapp et al. (ref. 1) for further details.

Densification of the preform can be achieved through a combination of CVD and/or repetitive-pitch impregnations. A final density of $1.9 \mathrm{~g} / \mathrm{cc}$ is achievable.

\subsubsection{Conclusions}

The unique combination of properties that may be achieved from carbon-carbon composites makes them an attractive choice for PFCs. Materials-property requirements for limiter and diverter applications have been discussed. It is evident that the selection of fiber type and processing temperatures will have to be a compromise. However, with currently available fiber and processing technologies, the development of carbon-carbon materials for PFCs in a fusion reactor is a realistic goal. 


\subsection{FABRICATION STUDIES}

At the present time, an active program exists to keep commercial suppliers aware of our plans and test results. To date, the materials received for this program have been supplied to us by the vendors at no cost. As the program proceeds and becomes more definitive, it is expected that vendors will continue to play an active and vital role through the mechanisms of competitive requests for proposals when develcpment work is needed, or requests for quotations when a target material specification can be supplied.

In addition to this vendor support, two promising studies are in progress under the DOE's SBIR Program. These are summarized below.

\subsubsection{NAMCO, SBIR Program}

NAMCO's SBIR Program is focused toward providing satisfactory materials for the ITER and BPX. NAMCO has developed 2-D, carbon-carbon composites with high-thermal-conductivity pitch fibers. The processing selected for these composites was aimed at enhancing the thermal conductivity of the composites. Three-dimensional, carbon-carbon composites are currently being processed with high-thermal-conductivity pitch fibers. NAMCO is also developing novel composites to enhance the z-direction thermal conductivity. The processing of the composites ensures good mechanical properties along with high thermal conductivity. These composites will be evaluated for application in ITER and BPX. A data base on 20 high-conductivity, highstrength, carbon-carbon composites fabricated with a variety of pitch fibers is available.

\subsubsection{Applied Sciences, Inc., SBIR Program}

Applied Sciences, Inc., produces vapor-grown carbon fibers (VGCF) possessing extremely high thermal conductivity [approximately $2000 \mathrm{~W} /(\mathrm{m} \cdot \mathrm{K})$ at room temperature], low CTE $(-1$ and $9 \times 10^{-6} / \mathrm{K}$ in the axial and transverse directions, respectively), and because of their enhanced crystallinity, potentially good radiation resistance. The production of VGCF from the vapor-phase pyroloysis of hydrocarbon gas gives VGCF a great deal of processing versatility.

Applied Sciences' current Phase I project involves utilizing the excellent properties of VGCF along with its production flexibilty to produce a 3-D, carbon-carbon composite, PFC material. The VGCF fibers will be grown through the thickness of a pre-existing carbon scaffolding, which acts as a substrate for the fiber growth. The material will then be densified via CVD to form a 3-D, carbon-carbon composite with high-thermal-conductivity VGCF fibers oriented through the thickness of the tile. This fiber orientation maximizes heat transfer through 
the PFC to the underlying cooling/support structure and will also reduce eddy-current-induced forces in the plane of the PFC because of the fibers' lower electrical conductivity in the transverse direction. Applied Sciences anticipates thermal conductivity through the thickness of the material to approach $500 \mathrm{~W} /(\mathrm{m} \cdot \mathrm{K})$. Moreover, the composite will possess excellent thermal shock resistance.

\subsection{IRRADIATIONS IN FFTF}

Carbon-carbon composite materials have been included in MOTA capsule irradiations in the last two FFTF cycles (10 and 11). Cycle 10 (approximately $10 \mathrm{dpa} C$ at $400^{\circ} \mathrm{C}$ ) was completed in January 1989, and cycle 11 irradiations are expected to be completed in March 1991. Descriptions of the cycle 10 materials are given in Table 2 . The materials used in cycle 10 experiments were provided gratis by various fabricators, but the materials were not produced for radiation-damage resistance, nor were the fabricators aware that such tests were contemplated. Nevertheless, the specimens are a very good representation of present vendor materials. The results from the cycle 10 post-irradiation examination (PIE) are discussed in Appendix 2.

Table 2. HHF specimens in FFTF cycle 10 MOTA-1F

\begin{tabular}{lcl}
\hline Identity & $\begin{array}{r}\text { Fluence } \\
\text { (dpa C) }\end{array}$ & \multicolumn{1}{c}{ Description } \\
\hline CC1 & 12.3 & NAMCO 2-D satin weave \\
CC2 & 12.1 & NAMCO 2-D satin weave \\
CC3 & 11.5 & BFG 2-D satin weave \\
CC4 & 11.4 & BFG 2-D satin weave \\
CC5 & 11.7 & BFG 2-D staple knit \\
CC6 & 11.4 & FMI 4-D coarse weave \\
CC7 & 10.9 & FMI 4-D fine weave \\
CC8 & 11.1 & HITCO 2-D \\
CC9 & 10.5 & Kaiser 2-D \\
CC10 & 10.1 & LTV/Vought 2-D \\
\hline
\end{tabular}

Irradiation dimensional changes of polycrystallin z graphites are characterized by low-fluence contraction to a turnaround point followed by swelling at higher fluences. Carbon-carbon composites may exhibit the same behavior, so that with data at a single fluence level, it is 
impossible to conclude if the material has just low-dimensional change or if it has gone through the turnaround point and is returning toward its original volume. Carbon-carbon composite materials for cycle-11 MOTA capsules HA07 and HA08 were supplied by ORNL and included grade H-451 graphite (reference material); three Fiber Materials Incorporated (FMI) composites [i.e., 3-D, orthogonal; orthogonal, fine-weave 222 (pitch fiber); and 223 (PAN fiber)]; and random fiber composite (RFC). The cycle-11 capsules are expected to achieve a maximum fluence of $30 \mathrm{dpa}$ at a temperature of $600^{\circ} \mathrm{C}$.

Carbon-carbon composite materials are to be included in FFTF cycle 12, which is expected to commence in early April 1991. The planned irradiation temperature is $430^{\circ} \mathrm{C}$, and the maximum fluence will be 2 to $7 \mathrm{dpa} \mathrm{C}$, which is relevant to the ITER (physics phase) and BPX. A test materials matrix has been assembled by ORNL and will include carbon materials which, based upon previous data (refer to Sect. 5.5), are most relevant to PFC needs. These include: FMI 3-D, fine-weave, pitch-fiber composites that have been heat treated to four different temperatures $\left(2400,2550,2750\right.$, and $3000^{\circ} \mathrm{C}$ ); FMI 3-D, fine-weave composite with P120 (highconductivity) pitch fibers in the $z$ direction; and P75 pitch fibers in the $\mathrm{x}$ and $\mathrm{y}$ directions. Specimens from DOE-SBIR contractors (including pitch-fiber, angle-interlock material) and 2-DP75/P130X (ultra-high-conductivity) pitch-fiber composites from NAMCO and the VGCF composites from Applied Sciences, Inc., are also part of the test matrix. Moreover, samples of free pitch fibers with a range of elastic moduli and reference graphites (H-451 and GraphNOL N3M) have been supplied by ORNL. Carbon-carbon composite materials brazed onto several different copper-based substrates have been provided by Sandia National Laboratory-Albuquerque (SNLA).

The fluences and irradiation temperatures for all planned and completed FFTF (and HFIR) irradiations are summarized in Fig. 5.

The FFTF has certain unique advantages for irradiations in this program. First, capsules can operate up to temperatures of $1500^{\circ} \mathrm{C}$, whereas HFIR currently has utilized capsules only up to $900^{\circ} \mathrm{C}$ in the target region. Secondly, specimen swelling with potential rupture of capsules containing only carbon materials is not a "safety" problem at FFTF with its sodium coolant. Hence, irradiations to high fluences and high damage levels can be performed without risk. Conversely, capsule rupture in HFIR with its water coolant is not permissible. Thus, neither HFIR (nor the EBR-2) can fully replace the FFTF in cur irradiation program. 


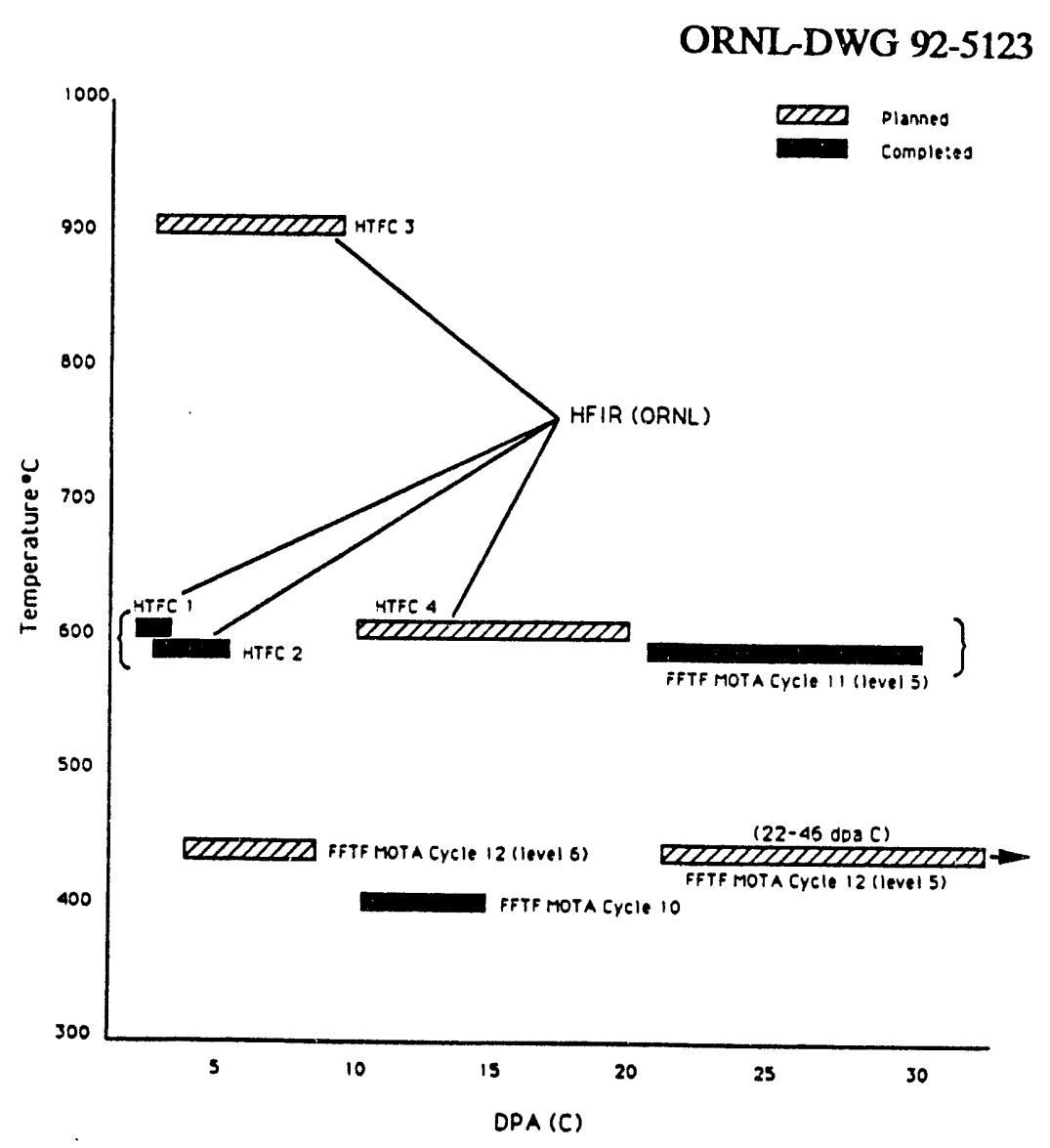

Fig. 5. The relationship between planned and ongoing graphite, carbon-carbon composite, and carbon fiber irradiations in the HFIR and FFTF.

\subsection{IRRADIATIONS IN HFIR}

Currently, four HFIR target irradiation experiments are planned, designated HTFC 1, 2, 3 , and 4. Of these, HTFC 1 and 2 have been constructed and have completed their scheduled irradiations.

The fibers and carbon-carbon-composite materials and reference graphites included in HTFC 1 and 2 are listed in Table 3. Capsule HTFC 3 is currently under construction and will be irradiated at $900^{\circ} \mathrm{C}$ to a peak fluence of $9 \mathrm{dpa}$, which is relevant to the engineering phase of the ITER. Likewise, HTFC 4, when constructed, will be irradiated to high fluence (but at the lower temperature of $600^{\circ} \mathrm{C}$ ) and will be a severe test of the newly developed carbon-carbon materials. PIE of HFIR carbon-carbon composite specimens will include thermal conductivity, dimensional changes, density, elastic constants, and electrical resistivity. 
Table 3. Materials included in the ORNL Program

\begin{tabular}{lcc}
\hline \multicolumn{1}{c}{ Architecture } & Fiber type & $\begin{array}{c}\text { HT temperature } \\
\left({ }^{\circ} \mathrm{C}\right)\end{array}$ \\
\hline & Carbon-carbon composites & \\
2-D 8H satin & Pitch & 3000 \\
2-D 8H unbalanced & Pitch & 3000 \\
3-D fiber weave (ortho) & Pitch & $2650 / 3275$ \\
3-D fiber weave (ortho) & PAN & $2650 / 3275$ \\
Fiber carbon (RFC) & PAN & 2650 \\
Fiber carbon (UFC) & PAN & 3275 \\
& Fibers \\
& Pitch: E $=25,50,100,130 \times 10^{6}$ psi \\
& PAN: HS, F3-0 \\
& Reference graphites \\
& GraphNOL N3M \\
\hline
\end{tabular}

The HFIR reactor has a major advantage over the FFTF in that the standard operating cycle is approximately 1 month, compared with a 12-month cycle for the FFTF. Therefore, HFIR experiments to fusion-relevant fluences may be obtained in just 1 or 2 months. The HFIR is currently operating normally and has completed 16 cycles without problems. Should HFIR be unavailable in the future, several alternative materials test reactors could be utilized. These include the Advanced Test Reactor (ATR) at Idaho Falls, the High Flux Reactor (HFR) at Petten in The Netherlands, the Japan Materials Test Reactor (JMTR) at Tokai, and the Phoenix Reactor in France.

\subsection{AN IRRADIATION-RESISTANT CARBON-CARBON COMPOSITE PFC MATERIALS CONCEPT}

Based upon the limited data currently available and our understanding of the effects of irradiation on carbon-carbon composite materials (as discussed in Appendix 2), it appears that the following architectural features are desirable in a carbon-carbon composite material optimized for radiation stability. 


\subsubsection{Highly Crystalline Pitch ibers}

These fibers possess the highest degree of crystallinity and are thus expected to exhibit minimal irradiation-induced dimensional changes. Moreover, such fibers possess the highest thermal conductivities and are therefore highly desirable.

\subsubsection{3-D or Interlocked Architecture}

Either interlocking or 3-D weaves will reduce separation of the cloth layers or $x-y$ fibers in the composite material. A high-fiber fraction in the PFC thickness z-direction will be required to attain the desired thermal conductivities.

\subsubsection{Fine Unit-Cell Size}

A fine unit cell size is desirable because of the relatively thin section of the PFCs. Moreover, experimental evidence from the FFTF cycle-10 MOTA experiment demonstrated the desirability of a fine unit-cell size.

\subsubsection{High Final Heat-Treatment Temperature}

A final heat-treatment temperature in excess of $2800^{\circ} \mathrm{C}$ will promote maximum crystallinity in the fibers and matrix of the composite, thus enhancing radiation stability.

\section{MATERIAL PROPERTY GOALS}

At the present time, the two goals considered to be paramount to the use of carboncarbons in fusion energy applications are thermal conductivity and neutron radiation-damage resistance. The use of carbon-carbons for high-thermal-conductivity applications (e.g., the BPX diverter) is necessarily limited to very-low-neutron fluences, whereas wall tiles for an application such as ITER's engineering phase must necessarily withstand high-neutron fluences. Other thermomechanical properties should be attainable without difficulty.

\subsection{THERMAL CONDUCTIVITY}

\subsubsection{Estimation of Attainable Conductivity for a 2-D Composite}

A major advantage of carbon-carbons is that the microstructure can be tailored to optimize specific properties by choice of fiber, matrix, and architectural design. In this way, fibers can be concentrated in a given direction, thus enhancing the thermal conductivity in that direction. By 
employing a highly graphitic fiber, say Amoco P-130X pitch fibers, in the warp direction of a heavily unbalanced cloth, the thermal conductivity in the warp direction can be increased at the expense of the fill direction. Using a rule-of-mixture calculation, we can estimate the achievable thermal conductivities in a 2-D composite as a function of fiber volume and warp/fill ratios, as shown in the accompanying Table 4. Of considerable interest is the last entry in the table, which presents the experimentally determined values for an actual composite structure. This measured conductivity should be compared with the calculated value for the closely corresponding, assumed structure appearing earlier in the table.

The entries in Table 4 are calculated using an axial fiber conductivity of $1180 \mathrm{~W} /(\mathrm{m} \cdot \mathrm{K})$ [ref. 2], a radial fiber conductivity of zero, and an isotropic matrix assumed to resemble nuclear graphite grade $4-451$ with a conductivity of $120 \mathrm{~W} /(\mathrm{m} \cdot \mathrm{K})$. For these 2-D composites, the upper limit on room-temperature conductivity appears to be about $700 \mathrm{~W} /(\mathrm{m} \cdot \mathrm{K})$.

\subsubsection{Future Plans}

At the present time, a program is under way through an SBIR contract directed by NAMCO with the aim of attaining or surpassing the maximum values given in Table 4. Further details may be found in Sect. 5.2.1. In addition, vapor-grown filaments offer a potentially higher thermal conductivity than the pitch-based fibers. This area is also the subject of an SBIR contract, further details of which may be found in Sect. 5.2.2.

\subsection{RADIATION-DAMAGE RESISTANCE}

\subsection{Estimation of Radiation-Damage Resistance Attainable}

The development of damage resistance in bulk graphites and carbon-carbon composites is based on two very different considerations. We first review the logic and results for minimizing damage in bulk graphite.

Bulk graphite will be subject to mechanical failure whenever its worst-behaved direction begins to undergo radiation-induced expansion, a fact recognized years ago in the Hanford Production Reactors. The industry was loath to change from these so-called AGOT graphites because of the extensive data base that had been acquired over the 1945 to 1970 period. Clearly, the first step was to go to graphites that were isotropic, at least in the gross sense, and this step was accomplished in England in the late 1960s with the development of a nuclear graphitc based on gilso-carbon coke filler. In the United States, the development of H-451 graphite for Fort 


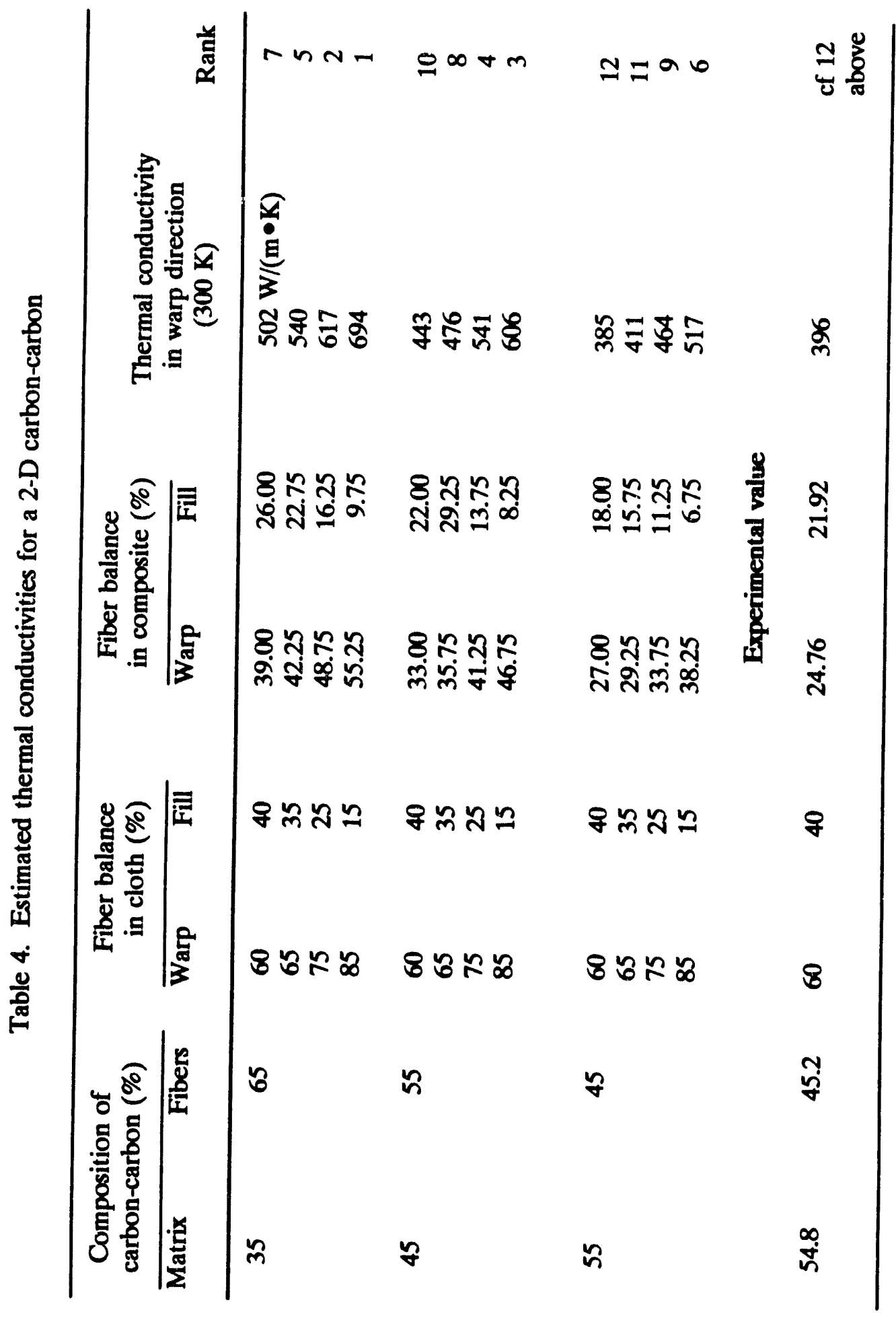


St. Vrain core-replacement segments achieved the same objective but was based on specially developed petroleum coke rather than gilso-carbon.

The characteristics of $\mathrm{H}-451$ graphite, which give it strong resistance to damage, are as follows: (1) isotropy on a macroscopic scale, (2) isotropy on a microscopic scale to prevent buildup of internal strains over macroscopic distances, and (3) maximum crystallinity consistent with isotropy and thermal expansion coefficients.

For carbon-carbon materials this approach is obviously not possible, in that the desirable characteristics of the composite depend essentially on the anisotropy inherent in the fiber. We are thus left with having to tie the composite together with fibers in at least three orthogonal directions and further developing the fiber crystallinity to the highest degree possible. The purpose for the latter step is the fact that the more perfect the crystal, the less becomes the radiation-induced distortion. In actuality, this opens up the possibility of a carbon-carbon having a longer life than the bulk graphite to the extent the intrinsic crystal damage is less severe and reducible by creep, while at the same time the fibers prevent the destructive expansion in the bulk graphite.

The most common mode of failure of carbon-carbons is shear failure between the yarn bundle and the matrix. This permits fiber failure at weak points, leading to fiber pullout as fracture proceeds. The radial expansion of the filaments due to radiation damage may reduce the failure at the fiber-matrix interface and thus lengthen the time-to-gross failure. But, it would seem safe to target for gross failure at the point at which the matrix fails, and this presumably would be similar to the lifetime of the bulk graphites. On this basis, a reasonable goal for carbon-carbon lifetime under irradiation would be that of a bulk graphite with similar matrix structure. While this argument applies to matrices from pitch precursors, it does not give us any prediction on the behavior of pyrolytic carbon matrices with the multiplicity of structures thus obtainable.

Figure 6 presents radiation-induced dimensional behavior of the best-behaved bulk graphite at two irradiation temperatures. Lifetime is defined as the point at which the volume change returns to zero (in the present example, about $30 \mathrm{dpa}$ at $600^{\circ} \mathrm{C}$ and $20 \mathrm{dpa}$ at $875^{\circ} \mathrm{C}$ ). As mentioned in Sect. 5.5, data out to about $10 \mathrm{dpa}$ in the MOTA experiments at least suggest the carbon-carbon lifetime argument is not negated up to the present data limitations. 


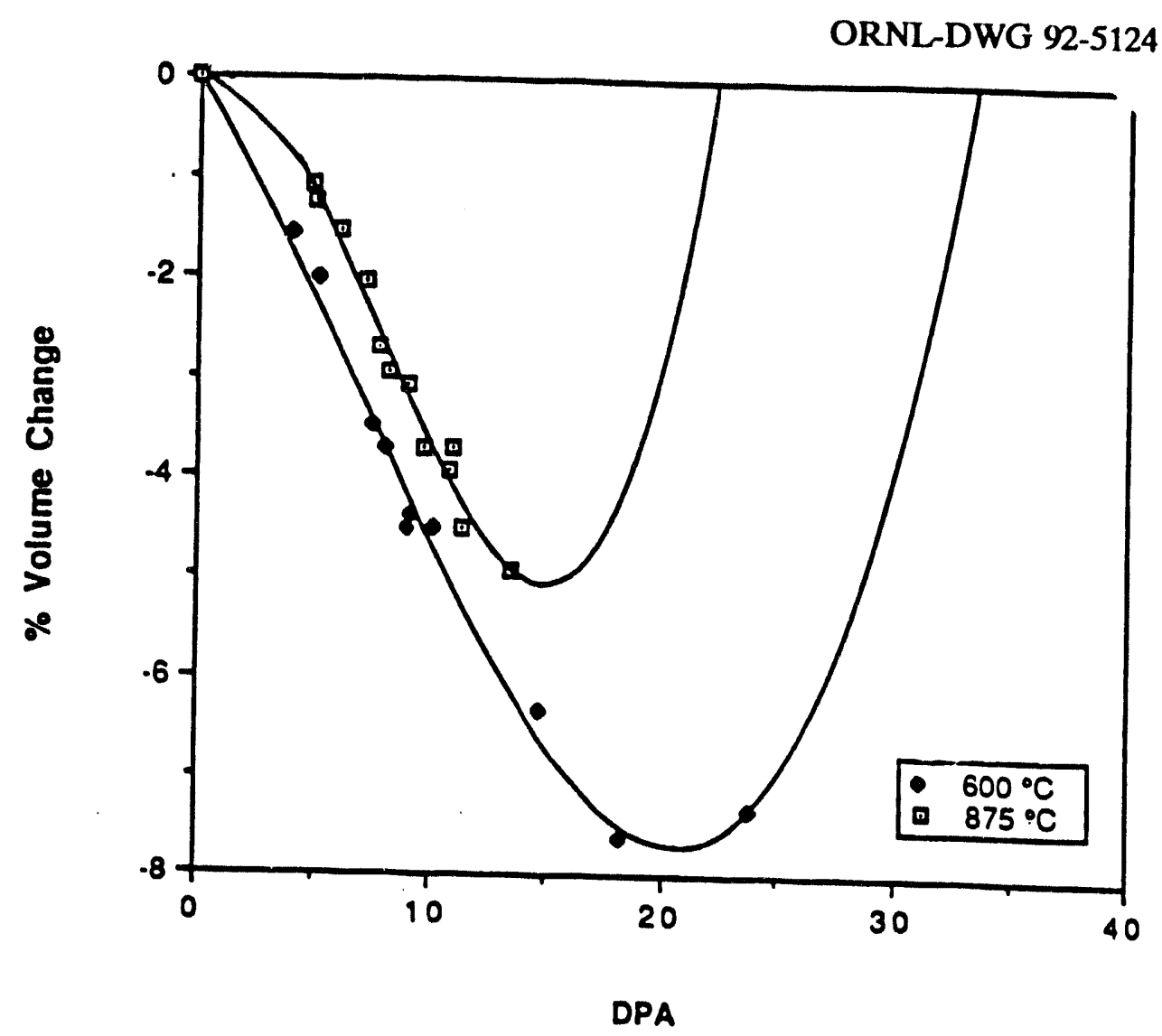
N3M graphite.

Fig. 6. Neutron irradiation-induced volume changes in GraphNOL

\subsection{DOPED MATERIALS FOR EROSION AND OXIDATION CONTROL}

Interest in doped graphite or carbon-carbons for fusion energy applications first emerged from Russian reports that boron-containing graphite exhibited lower erosion rates than an equivalent boron-free graphite. This information may be coupled with the known behavior of boron doping for graphitic thermocouples and the reduction in both air and steam oxidation rates for boron-doped materials. More recently, Y. Hirooka at the University of California at Los Angeles (UCLA), working with boronated graphites fabricated in Japan, confirmed in the laboratory that the erosion rate has indeed been reduced.

Within the last year, silicon doping of bulk graphite has also been observed to reduce steam oxidation rates. This is not to be confused with the coating of the geometric surface of graphite with siliconized silicon carbide for oxidation protection. Since the mechanism of oxidation protection is believed to be quite different between boron and silicon, there is no implication here that silicon should affect erosion. 


\subsubsection{Boronated Materials}

At the present time, the desirability of boronated graphite and carbon-carbons for plasmafacing materials is not yet established. Moreover, the boron additions can be made in two forms: $\mathrm{B}_{4} \mathrm{C}$ particulates in carbon or dissolved boron in graphite crystals. These two forms involve quite different carbon matrices, in that up to $2200^{\circ} \mathrm{C}$, the $\mathrm{B}_{4} \mathrm{C}$ is stable in carbon; above $2200^{\circ} \mathrm{C}$, the $\mathrm{B}_{4} \mathrm{C}$ dissolves up to a solubility limit of about $6 \%$ at $2500^{\circ} \mathrm{C}$. Above $2500^{\circ} \mathrm{C}$, the boron-carbon solid solution recrystallizes, and the original texture of the graphite is completely transformed. Thus, once boron is introduced into the graphite of carbon-carbons, the maximum heat-treatment temperatures are determined by the final structure required.

Under irradiation in a fusion spectrum, carbon itself undergoes the reactions:

$$
{ }^{12} \mathrm{C}(\mathrm{n}, \alpha){ }^{9} \mathrm{Be}
$$

and

$$
{ }^{12} \mathrm{C}\left(\mathrm{n}, \mathrm{n}^{\prime}\right) 3 \alpha
$$

both of which will produce damage in graphite in excess of the pure neutron on carbon damage produced in a fission reactor. The thermal neutron reaction:

$$
{ }^{10} \mathrm{~B}(\mathrm{n}, \alpha){ }^{7} \mathrm{Li}
$$

also produces extensive additional damage in graphite if the recoil $\alpha$ particles are not retained in a $\mathrm{B}_{4} \mathrm{C}$ particulate.

It thus appears best, at the present time, to delay any serious studies of neutron damage in boronated materials until the following two "questions" are answered unambiguously:

1. Is it indeed desirable, for other reasons, to have boron-containing materials in plasma-facing applications?

2. What are the best forms of carbon-carbon established for applications involving neutron and ion irradiation?

At this point, the rather delicate irradiation experiments can be performed, involving carbon-carbons in the three forms of no boron, normal boron, and pure ${ }^{10} \mathrm{~B}$, all with similar structures.

Quite aside from this, the interest in boron doping to utilize the ${ }^{10} \mathrm{~B}(\mathrm{n}, \alpha)^{7} \mathrm{Li}$ in a fission reactor to produce the equivalent of the carbon $(n, \alpha)$ reactions in a fusion spectrum remains a 
valid interest. In regard to this aspect of boronation (as well as the entire problem), W. C. Morgan at Battelle Pacific Northwest Laboratories (BPNL) is currently calculating the dpa for carbon on carbon, helium on carbon, and beryllium on carbon as a function of incident-ion energy. These are then being adapted to the HFIR target spectrum.

We therefore recommend that no detailed experiment planning be performed until these calculations have been completed and the roles of boronation and carbon-carbon structure have been established.

\subsubsection{Silicon-Doped Graphite}

Recently, in oxidation studies of graphite performed under the High-Temperature Gas-Cooled Reactor Program, it has been observed that bulk graphites containing silicon have oxidized under steam at significantly lower rates than the same material without silicon, even for purified graphites with total impurity levels in the range of $10 \mathrm{ppm}$ or less before the silicon addition. The amount of silicon required is no more than a few hundred parts per million. It has also been demonstrated that the silicon resides on the surface of pores rather than within the crystallites.

In view of the small amount of silicon required and its location in the material, it has been hypothesized that the silicon simply resides at active sites on the surface, thus blinding these sites to bonding by the water molecule. However, this mechanism has not yet been established and remains only a working hypothesis.

It is thus a possibility that silicon doping of graphite may affect the erosion rate and certainly will decrease the reaction rate with steam or oxygen. No work has yet been done under the Fusion Energy Program in the United States, but, clearly, specimens of doped and undoped graphite should at least cursorily be subjected to erosion, say, at UCLA.

\section{EUROPEAN AND JAPANESE FUSION CARBON-CARBON COMPOSITE PROGRAMS}

\subsection{EUROPEAN TECHNOLOGY PROGRAMS}

\subsubsection{Introduction}

The European tcchnology program was initially sei up to support the Next European Torus (NET) Fusion Reactor programs. The general approach has been to purchase available production graphites and carbon-carbon composite material from European suppliers and irradiate 
them in the HFR at Petten and the Phoenix Reactor. In a separate activity, Kernforschungsanlage $\mathrm{GmBH}$ (KFA)-Jalich is involved in a PFC materials program that includes carbon-carbon composites and graphites. Both programs are cescribed below.

\subsubsection{The NET Program}

\subsubsection{Materials}

The following materiak have been included in the NET Program:

1. Graphites: S1260, S1611, S1693, and 5890 (with and without SiC coatings) supplied by Le Carbone Lorraine; EK98 and V1325 supplied by Ringsdorf.

2. Carbon-carbons: Fine and coarse-weave, 3-D carbons supplied by SEP; A05 2-D carbons supplied by Le Carbone Lorraine.

\subsubsection{Irradiation Conditions}

Four experiments are known to be in progress (or complete) at the time of writing and are listed in Table 5.

Table 5. European irradiation experiments involving graphites and carbon-carbon composite materials

\begin{tabular}{|c|c|c|c|}
\hline Reactor & Fluence & $\begin{array}{c}\text { Temperature } \\
\left({ }^{\circ} \mathrm{C}\right)\end{array}$ & Status \\
\hline $\begin{array}{l}\text { HFR Petten } \\
\text { Phoenix } \\
\text { HFR Petten } \\
\text { HFR Petten }\end{array}$ & $\begin{array}{l}\leq 10 \mathrm{dpa} \\
\leq 30 \mathrm{dpa} \\
\leq 3 \mathrm{dpa} \\
10^{20} \text { to } 10^{24} \\
\text { neutrons/ms }\end{array}$ & $\begin{array}{c}1200 \\
500 \\
1500 \\
400,800,1200\end{array}$ & $\begin{array}{l}\text { Completed } 3 / 88 \\
\text { Completed } 5 / 88 \\
\text { Completed } 9 / 89 \\
\text { In progress }\end{array}$ \\
\hline
\end{tabular}

In addition to the above, a large program test matrix of carbon-carbon has been assembled for irradiation purposes. Specifically, this includes 2-D materials with variations in their fiber type, volume fraction, bundle size, and method of densification. These will be irradiated at temperatures from 400 to $1200^{\circ} \mathrm{C}$ to a maximum fluence of $\leq 3 \mathrm{dpa}$. Currently, however, there appears to be no plan to develop and irradiate advanced, 3-D, carbon-carbon composite PFC materiais. 


\subsubsection{The KFA Program}

\subsubsection{Materials}

This program (MAT6, D216-CERAM) is more limited in its irradiation, yet is more extensive in its pre- and post-irradiation testing. The materials included in the test matrix are similar to those in the NET team's program but also include samples of FMI's four-dimensional (4-D) materials (P25 pitch fibers):

1. fine-grained graphites: EK98 (Ringsdorf) and CL4890 (Le Carbone Lorraine),

2. super-fine-grained graphites: V1325 (Ringsdorf) and S1611 (Le Carbone Lorraine), and

3. carbon-carbon composites: Aerolor 05 (Le Carbon Lorraine), Aerolor 46 (Le Carbon Lorraine), and FMI 4-D, fine-weave (Fiber Materials, Inc.) CC1501G (SIGRI).

\subsubsection{Irradiation Conditions}

The conditions for irradiation testing included:

1. reactor: HFIR, position E5,

2. temperature: $1500^{\circ} \mathrm{C}$,

3. neutron fluence: 3 by $10^{25}$ neutrons $/ \mathrm{m}^{2}(\mathrm{E}>0.1 \mathrm{MeV})$, and

4. status: completed December 1989.

\subsubsection{Pre- and Post-Irradiation Examinations}

The following examinations are planned for the maierials in this experiment:

1. thermal shock testing (E-Beam),

2. thermal conductivity (RT to $1000^{\circ} \mathrm{C}$ ),

3. thermal expansion (RT to $1000^{\circ} \mathrm{C}$ ),

4. Young's modulus (Dynamic),

5. dimensional changes,

6. bend strength,

7. ceramography, and

8. scanning electron microscopy (SEM).

\subsubsection{Carbon-Carbon Composite PFC Material Development in Europe}

The development of 3-D, high-thermal-conductivity, carbon-carbon composites for fusion energy applications within Europe is being led by SEP in France, who, under contract to 
McDonnell-Douglas, has been manufacturing candidate-limiter materials for BPX. The carboncarbon material they are developing (SEP N1) has the following architecture: ${ }^{3}$

1. architecture, 3-D;

2. fibers, PAN;

3. fiber content, 30\% (approximately);

4. densification, CVD; and

5. final density, $1.8 \mathrm{~g} / \mathrm{cm}^{3}$.

Given the small total fiber content and low thermal conductivity of PAN fibers, it is unlikely that this material will achieve the high thermal conductivities required for BPX and ITER limiter and first-wall applications. Indeed, recent information from SEP and McDonnellDouglas indicates that SEP N1 is no longer a BPX PFC candidate material.

Other European suppliers have the capability to manufacture 3-D materials but, to date, do not appear to have been utilizing the mesophase-pitch fibers required for PFCs.

\subsection{THE JAPANESE PROGRAM}

The Japanese have an active carbon-carbon composite program. First-wall and diverter materials have been developed for use in the upgrade of JT-60. An extensive materials performance evaluation and assessment program was carried out at JAERI's Naka Fusion Research Establishment. The materials included in the JAERI test matrix are summarized in Table 6.

Table 6. Carbon-carbon composite materials included in the JAERI Program

\begin{tabular}{lll}
\hline \multicolumn{1}{c}{ Material } & \multicolumn{1}{c}{ Manufacturer } & \multicolumn{1}{c}{ Description } \\
\hline CC-312 & Showa Denko & 2-D C/C composite \\
CX-2002U & Toyo Tanso & 2-D C/C composite \\
MCI-Felt & Mitsubishi Kasei & $1-\mathrm{D} \mathrm{C/C} \mathrm{composite}$ \\
PCC-2S & Hitachi Kasei & 2-D C/C composite \\
MFC-2 & Mitsubishi Kasei & $1-\mathrm{D} \mathrm{C/C} \mathrm{composite}$ \\
Aerolor 05G & Le Carbone Lorraine & 2-D C/C composite \\
\hline
\end{tabular}


In addition to the above carbon-carbon composites, a series of isotropic graphites were included in the evaluations. Key mechanical and thermal-physical properties are shown in Table 7. The JAERI evaluation included measurement of purity (ash content), density, electrical resistivity, Young's modulus, thermal conductivity, CTE, specific heat, Foisson's ratio, strength, thermal shock resistance, and outgassing rate. The selection of materials for JT-60U was made on the basis of thermal conductivity, thermal shock resistance, and mechanical strength. The findings of this investigation were reported by Yamamoto et al. ${ }^{4}$ A 2-D, felt-type, carbon-carbon composite with a room-temperature thermal conductivity in the range of 300 to $400 \mathrm{~W} / \mathrm{m} \cdot \mathrm{K}$ was recommended for the diverter. For the first wall, two grades of isotropic graphite were recommended.

Two Japanese PFC materials irradiation programs are currently ongoing. The Monbusho program is utilizing the FFIF MOTA at Hanford for irradiation experiments, whereas the JAERI program is utilizing its JMTR and JR2 reactors for its irradiation experiments. Two MOTA capsules have been allocated to the Monbusho PFC program in the forthcoming cycle 12 of FFIF. Both capsules are at level 6 and will receive approximately 2 dpa (C) at a temperature of approximately $400^{\circ} \mathrm{C}$. A number of Japanese carbon-carbon composites are in the cycle 12 MOTAs, including CC-312, MFC-1, and CX-2002U. Additionally, two grades of pyrolytic graphite will be irradiated. The JAERI program includes the materials listed in Table 7.

One Japanese carbon-carbon composite is a candidate material for the BPX diverter. The material, designated MKC-1PH, is manufactured by Mitsubishi Kasei and is a uni-directional composite made with coal-tar, pitch-based carbon fibers. It is attractive because it offers high thermal conductivity $\left(470 \mathrm{~W} / \mathrm{m} \cdot \mathrm{K}\right.$ at $350^{\circ} \mathrm{C}$ and $180 \mathrm{~W} / \mathrm{m} \cdot \mathrm{K}$ at $\left.1500^{\circ} \mathrm{C}\right)$ combined with relatively large, fabricable sizes. This material has been under examination at ORNL for McDonnell Douglas Astronautics and will be included in the matrix of materials ORNL is assembling for inclusion in two of the FFTF cycle-12 MOTA capsules.

\subsection{THE PROSPECTS FOR DEVELOPMENT OF CARBON-CARBON PFC MATERIALS OUTSIDE OF THE UNTTED STATES}

Our European partners in the ITER project have not been able to produce a carboncarbon compcsite material with properties suitable for ITER's PFCs. The failure of SEP to deliver candidate materials to the BPX program only serves to highlight this concern. Russia has only a limited technology base in carbon-carbon composites and, thus, cannot be relied upon for solutions. Japan, however, does have a strong fiber and composite industry. 


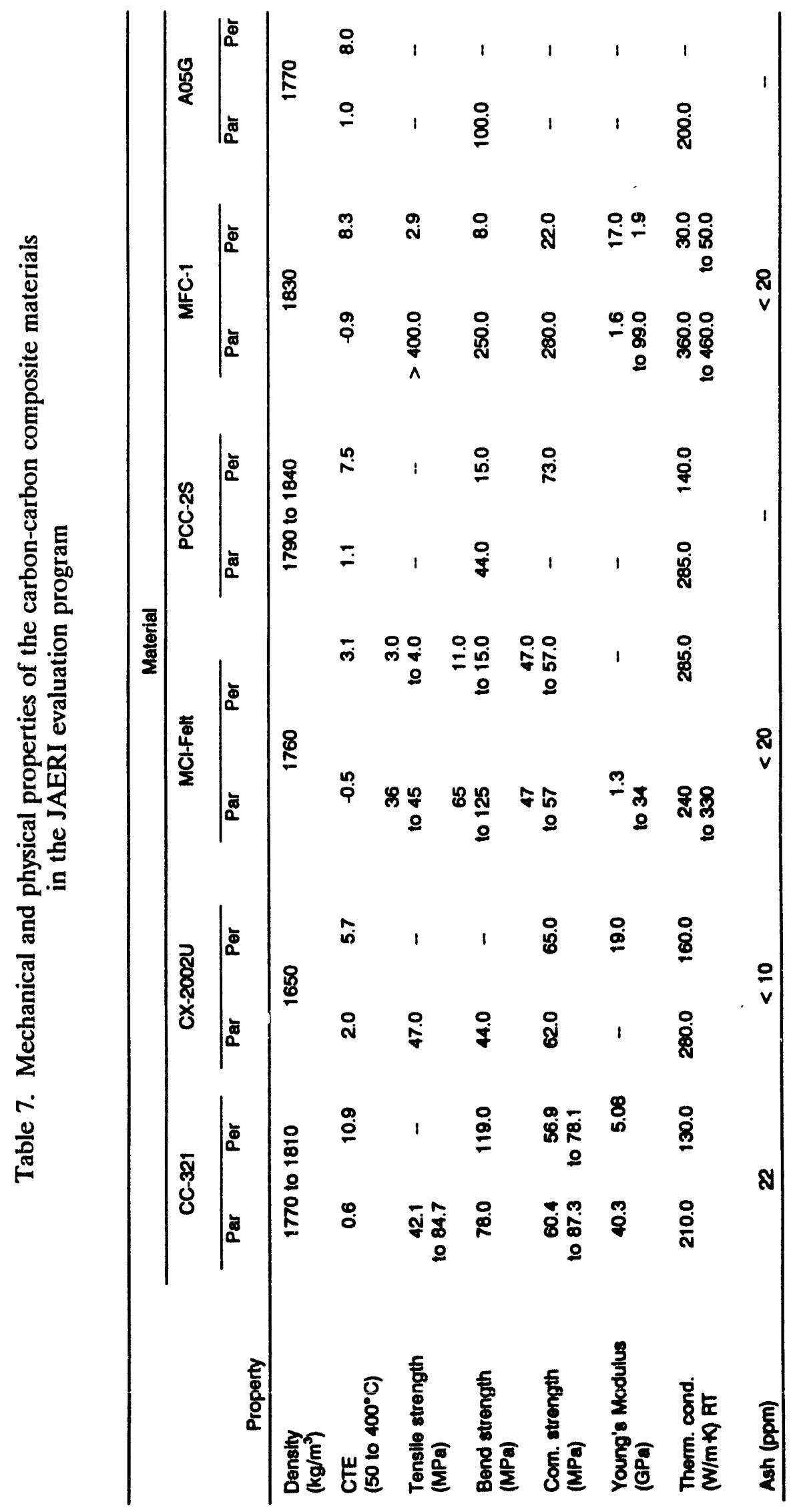


To date, their carbon-carbon composites have not been of the advanced (3-D, woven) type but rather of the simpler 2-D and random fiber types. Japanese pitch and vapor-grown fibers are available, and companies such as Mitsubishi are actively promoting high-conductivity fibers. The Japanese, therefore, could develop suitable PFC materials but not as quickly as could be achieved in the United States. The successful development of carbon-carbon composite PFC materials is most likely to be accomplished in the United States.

\section{CARBON-CARBON COMPOSITE MATERIALS DEVELOPMENT COST AND SCHEDULE}

In Sect. 4 (Program Logic; Technical Approach) an approach was outlined for the development of carbon-carbon composite materials for first-wall applications. The program described (Fig. 2), and the sequence of R\&D activities for selected carbon-carbon materials concepts (Fig. 3), must be related to the ITER design schedule if suitable materials are to be developed in a timely manner. The ITER design schedule is presented in Fig. 7. Currently, the ITER project is in the Protocol I phase. A five-year design phase is scheduled to commence at the beginning of CY 1992 and terminate at the end of CY 1996. Ideally, a full-design data base should be available for the first-wall and diverter materials by the end of year three of the design activity (end of CY 1994).

During the ITER Conceptual Design Phase, much was accomplished in the R\&D of carbon-carbon composite materials for the first wall. Based on these preliminary data (some of which are reported here and some that will become available in the very near future), we are able to define candidate materials, or in the terminology of Fig. 7, materials concept 1 . Moreover, the materials design requirements have been formalized, i.e., operating temperatures, heat load, neutron flux, erosion rates, etc. Thus, we may reasonably assume that by the end of calendar year (CY) 1991, ORNL can have completed the preparation of concept 1 specifications for the fist-wall and diverter carbon-carbon composites and fabrication contracts awarded on a competitive basis [request for quotation (RFQ)]. This is shown graphically in Fig. 7. Our schedule allows 12 months for the manufacturing of these first prototypical physics-phase materials. For the first wall, this should undoubtedly be ample time. However, the manufacture of a diverter material represents a far more significant challenge, and 12 months may thus be optimistic.

Initial testing of concept 1 materials will be limited to those properties identified as of primary concern (refer to Table 1), i.e., irradiation dimensional stability and thermal conductivity 


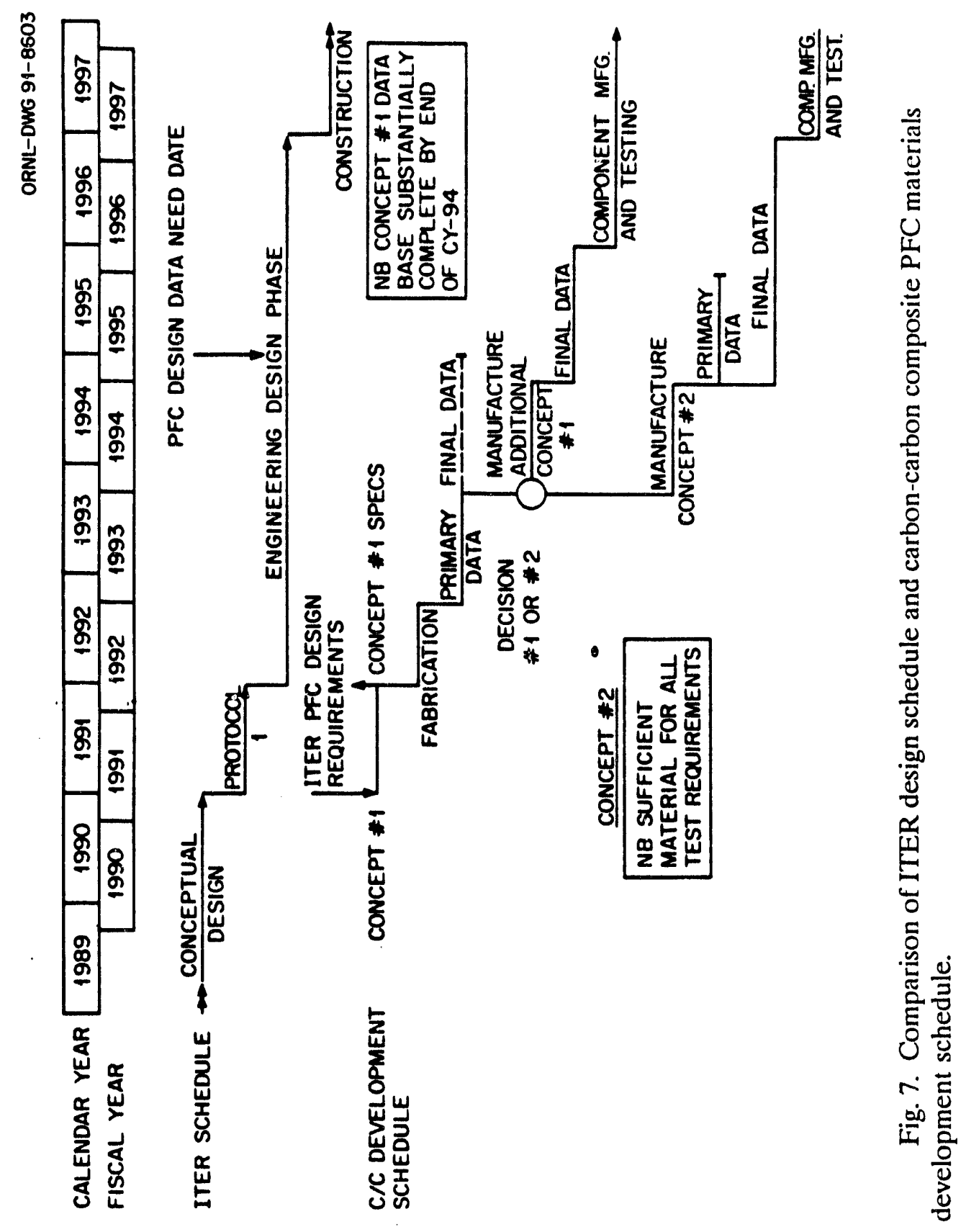


(as fabricated and postirradiation). Moreover, these properties can be expeditiously tested and evaluated at ORNL. The completion of preliminary testing corresponds with the first decision point shown in Fig. 3. If the concept 1 materials meet or exceed the design requirements, additional materials would be purchased, and secondary and tertiary properties (as defined in Table 1) would be determined by other laboratories participating in the U.S. Fusion Energy PMI/PFC Materials Program. Thus, an engineering design data base could be developed and be substantially complete by the end of CY 1994.

However, if the concept 1 material does not meet the specified design requirements, a second round of materials development/manufacture will be necessary. The manufacture of a concept 2 material is indicated on the lower line in Fig. 7. Should the development of a concept 2 carbon-carbon composite become a sine qua non, preliminary data from ORNL would be available at the end of CY 1994. Moreover, a full engineering design data base would not be available until the end of CY 1996. It is anticipated that sufficient definition of concept 2 would exist due to the focussing effect of our concept 1 experience. Thus, acquisition of final data will be performed in parallel with the preliminary data acquisition. Obviously, a sufficient quantity of concept 2 material must be procured to facilitate this.

A second major decision point may be identified at the completion of engineering data base acquisition (end of CY 1995 for concept 1, end of CY 1996 for concept 2), whereupon prototypical components have to be manufactured to facilitate component testing and qualification prior to installation during the construction phase.

It is evident from the preceding discussion that the schedule for development of U.S. carbon-carbon composite PMI/PFC materials in support of ITER (physics phase) is necessarily short. The successful development of composite PFCs in a timely fashion critically depends upon an adequate level of funding. Estimates of the required funding associated with this development program are supplied in Table 8. It is assumed that ORNL will be responsible for specification and procurement of concept 1 and, if required, concept 2 carbon-carbon composite materials. Moreover, ORNL will conduct the preliminary materials examination and assessment (thermal conductivity and radiation stability). Development of a full engineering data base will require the participation of DOE and other laboratories, and it is assumed that the cost of performing their portion of the carbon-carbon materials development program will be absorbed in their ITER R\&D task budgets. Alternatively, engineering design data, i.e., physical and mechanical properties, could be developed by the carbon-carbon composite vendor and DOE laboratories in a collaborative effort. 
Table 8. ORNL and materials costs associated with the development of carbon-carbon composite materials for ITER physics phase

\begin{tabular}{|c|c|c|c|c|c|}
\hline & \multicolumn{5}{|c|}{ Fiscal year } \\
\hline & $\begin{array}{l}1992 \\
(\$ K)^{*}\end{array}$ & $\begin{array}{l}1993 \\
\text { (SK) }\end{array}$ & $\begin{array}{l}1994 \\
\text { (SK) }\end{array}$ & $\begin{array}{l}1995 \\
\text { (SK) }\end{array}$ & $\begin{array}{l}1996 \\
\text { (SK) }\end{array}$ \\
\hline \multicolumn{6}{|c|}{ Concept 1 materials ${ }^{\dagger}$ only: } \\
\hline $\begin{array}{l}\text { ORNL } \\
\text { Material } \\
\text { Total }\end{array}$ & $\begin{array}{l}300 \\
\frac{280^{*}}{580}\end{array}$ & $\begin{array}{r}600 \\
\frac{0}{600}\end{array}$ & $\begin{array}{l}400 \\
500 \\
900\end{array}$ & $\begin{array}{r}400 \\
0 \\
400\end{array}$ & $\begin{array}{l}0 \\
0 \\
0\end{array}$ \\
\hline \multicolumn{6}{|c|}{ Concept 1 and 2 materials $^{\dagger}$ : } \\
\hline $\begin{array}{l}\text { ORNL } \\
\text { Materials } \\
\text { Total }\end{array}$ & $\begin{array}{l}300 \\
\frac{280}{580}\end{array}$ & $\begin{array}{r}600 \\
\frac{0}{600}\end{array}$ & $\begin{array}{l}300 \\
\frac{750^{+1}}{1050}\end{array}$ & $\begin{array}{r}600 \\
\quad 0 \\
600\end{array}$ & $\begin{array}{r}600 \\
0 \\
600\end{array}$ \\
\hline
\end{tabular}

* Fiscal year 1991 dollars. wall and diverter.

${ }^{+}$Assumes that there are two concept 1 and concept 2 materials, i.e., first

tPurchase of one diverter and one limiter materials blocks $(12 \times 12 \times 6$ in.).

** Purchase of two diverter and two limiter materiais blocks $(12 \times 12 \times 6$ in.).

"Purchase of three diverter and three li niter materials blocks $(12 \times 12 \times 6$ in. $)$.

ORNL costs are associated with the acquisition of primary data, which involves the preparation of HFIR target capsules. Three capsules are planned for preliminary data acquisition, these being at irradiation temperatures of 600,900 , and $1200^{\circ} \mathrm{C}$. The peak fluence of each capsule would be commensurate with the ITER physics-phase lifetime, which can be attained in a relatively short period (one to two months). Thermal conductivity measurements would be made before and after irradiation at temperatures up to $1600^{\circ} \mathrm{C}$. Additional irradiation experiments will be required to develop the full-design data base and if concept 2 materials are required. Two lines of total costs are shown in Table 8. The upper row assumes that concept materials are not required; the lower line assumes that concept 2 materials are required. In reality, these two total lines represent the minimum (concept 1 only) and maximum (concepts 1 and 2) costs. Should it be necessary to proceed to concept 2 with only one of the PFC materials (limiter or diverter), the costs will fall between the two totals. 


\section{CONCLUSIONS AND RECOMMENDATIONS}

1. The unique combination of properties that may be achieved from carbon-carbon composite materials makes them an attractive choice for PFCs.

2. A carbon-carbon composites, PFC materials, and data base development program similar to that described here should be instituted and pursued in the United States in order to ensure that adequate materials are available for the next generation of plasma-fusion devices.

3. Developmental carbon-carbon composite materials suitable for limiter and diverter applications in ITER and BPX should be sought from the commercial sector using the RFP/RFQ procedures.

4. Advanced carbon-carbon composite materials development should be continued and encouraged through DOE's SBIR Program.

5. Fundamental studies, such as tritium uptake and plasma erosion, should continue on a parallel path.

6. Initial carbon-carbon materials irradiation experiments in the HFIR and FFTF should be limited to peak fluences commensurate with the ITER physics phase and BPX PFC operational lifetimes.

7. Irradiation data are required over the temperature range relevant to ITER/BPX PFCs, i.e., 350 to $1700^{\circ} \mathrm{C}$. These experiments may be accomplished in the following test reactors:

a. temperatures $<1200^{\circ} \mathrm{C}$ in HFIR, and

b. temperatures $>1200^{\circ} \mathrm{C}$ in FFTF/EBR II.

8. Alternative reactors to HFIR, FFTF, and EBR II are ATR, HFR Petten, JMTR, and Phoenix.

9. No detailed experiment planning for boronated carbon-carbon composite materials is to be performed until BPNL's calculations have been fully reported, and the roles of boronation and carbon-carbon structure have been established.

10. Opportunities for collaboration with our ITER partners should be explored.

11. The CCWG should not be disbanded but charged with oversight responsibility in this technical area and further charged with producing an annual summary of technical accomplishments and proposed program changes. 


\section{REFERENCES}

1. J. W. Sapp, T. D. Burchell, C. R. Kennedy et al., "Status Report on Diverter and Inboard Limiter Material Selection for the Compact Ignition Tokamak," B-890602-PPL-02, TR-015, Plasma Physics Laboratory, Princeton University, Princeton, New Jersey, June 1989.

2. Personal communication, R. Bacon, AMOCO, to W. P. Eatherly, Oak Ridge Natl. Lab.

3. Private communication, Francois Christin, SEP, to T. D. Burchell, Oak Ridge Natl. Lab., February 1990.

4. M. Yamamoto, T. Ando, H. Takatsu et al., "Evaluation Test on First Wall and Diverter Plate Materials for JT-60 Upgrade," JAERI-M-90-119, Japan Atomic Energy Research Institute, Naka, Japan, July 1990. 


\title{
CARBON-CARBON COMPOSITE WORKING GROUP (CCWG) CHARTER AND MEMBERS
}

\author{
T. D. Burchell, ORNL, Chairman \\ R. A. Causey, SNL-L \\ W. P. Eatherly, ORNL \\ G. B. Engle, NAMCO \\ Y. Hirooka, UCLA \\ G. W. Hollenberg, B-PNL \\ J. W. Sapp, MDAC \\ M. A. Ulrickson, PPPL \\ J. B. Whitley, SNL-A
}

\section{CHARTER}

To define an integrated program of research sufficient to provide an engineering design data base for irradiated carbon materials relevant to the U.S. fusion energy program and to detail a strategy for the development, within the United States, of a high-thermal-conductivity, 3-D, carbon-carbon composite material suitable for first-wall applications in ITER and BPX. 


\section{APPENDIX 2}

\section{A REVIEW OF RADIATION DAMAGE DATA}

\section{A2.1 CURRENT IRRADIATION PROGRAM DIRECTION}

\section{A2.1.1 Radiation Damage in Graphites}

Impinging neutrons cause the displacement of carbon atoms from their equilibrium lattice positions into interlaminar sites. Consequently, the graphite crystal expands along its $\mathrm{c}$ axis and contracts in the two a directions (Fig. A2.1). Initially, for bulk graphites, the c-axis expansion is accommodated by the closure of internal voids that formed between the crystallites on their layer plane surfaces during manufacture. Graphites with near-single-crystal densities, e.g., HOPG, do not exhibit these interlayer voids, and thus the c-direction expansion for these graphites is comparatively large. At low exposures, the volume change behavior of bulk graphite is dominated by a-axis contraction, and the graphite undergoes volume shrinkage (densification). As the interlaminar voidage is closed, continued c-axis expansion causes the generation of internal cracking at crystallite boundaries, and the bulk graphite begins to swell (volumetric expansion), i.e., the density decreases. Properties that are sensitive to such structural changes, e.g., strength, elastic modulus, and thermal and electrical conductivity, are markedly altered by neutron irradiation.

\section{A2.1.2 Radiation Damage in Carbon Fibers}

The basic mechanism of radiation damage in carbon fibers is identical to that of graphites and may be interpreted through a microstructural model such as in Fig. A2.2. The crystallographic layer planes are modeled as a core-sheath arrangement, with the c-direction radial and the two a directions aligned axially and circumferentially. From single crystal behavior, we expect a-axis shrinkage and c-axis growth to occur. However, just as in the case of bulk graphites, the $c$-axis growth is initially accommodated by "interplaner" voidage. Therefore, macroscopically, we observe fiber axial shrinkage and fiber diameter shrinkage followed by swelling (due to c-axis growth). This type of behavior has been observed experimentally by Gray ${ }^{1}$ and Price et al. ${ }^{2}$ and is illustrated in Figs. A2.3 and A2.4. The diametral fiber behavior is shown by the data in Table A2.1 where shrinkage is the dominant process. However, three fibers listed as numbers 1,2 , and 6 show a turnaround to diametral growth at higher fluences.

The crystallite size of carbon materials has been shown to markedly influence the rate of neutron damage accumulation, as shown schematically in Fig. A2.5. Essentially, interstitial defects 

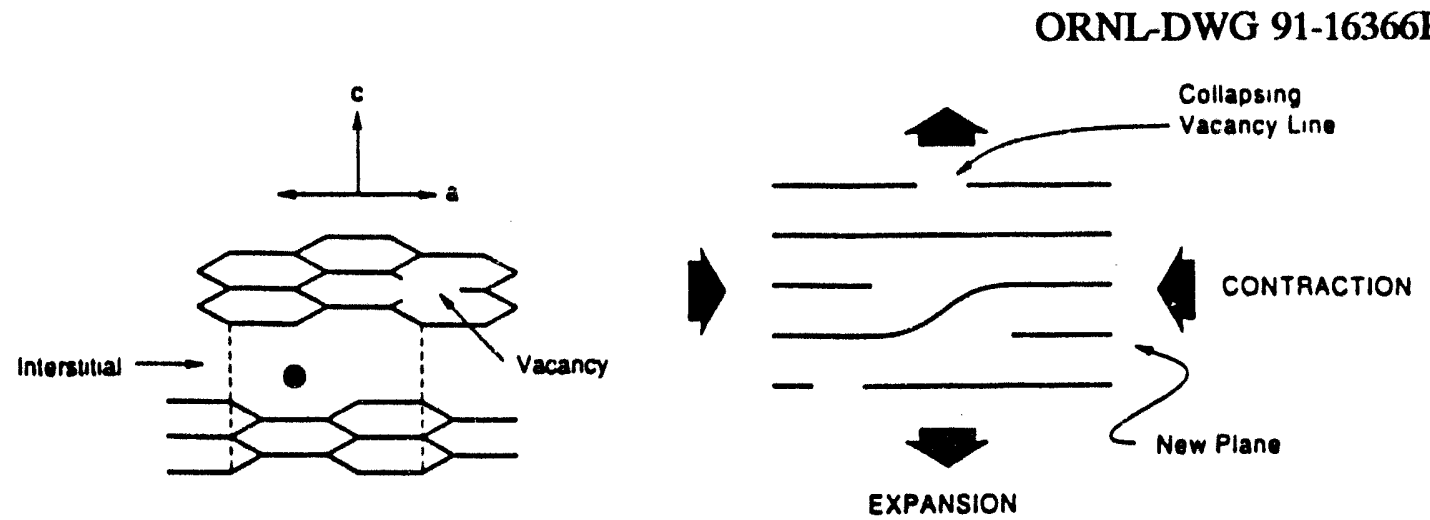

Fig. A2.1. Radiation damage in graphites.

ORNL-DWG 91-11079A

- Simplified fiber microstructure:
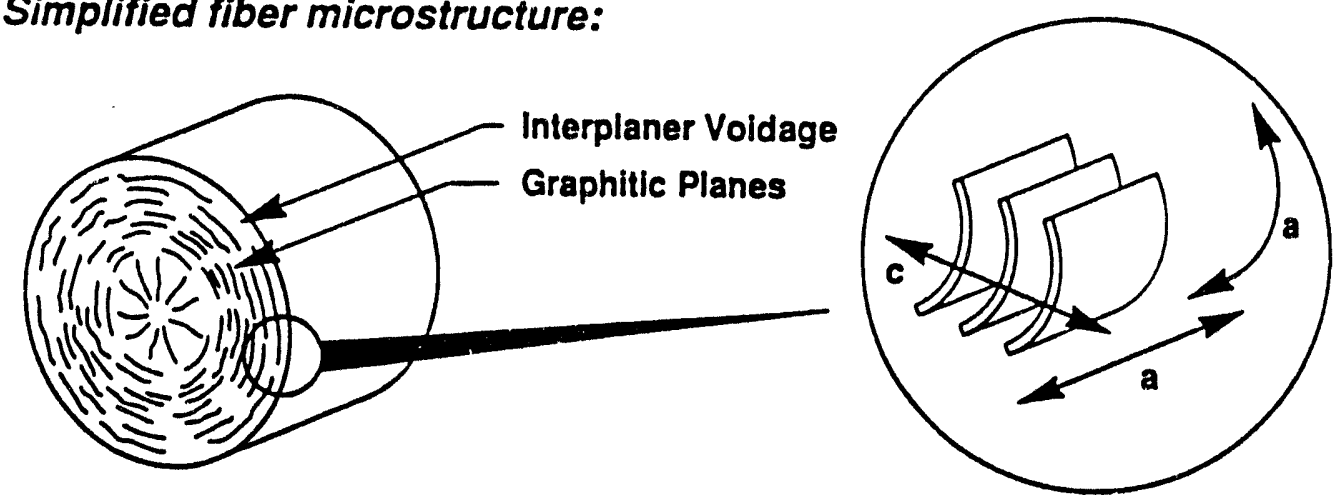

"Core-Sheath Model"

Fig. A2.2. Radiation damage in carbon fibers. 


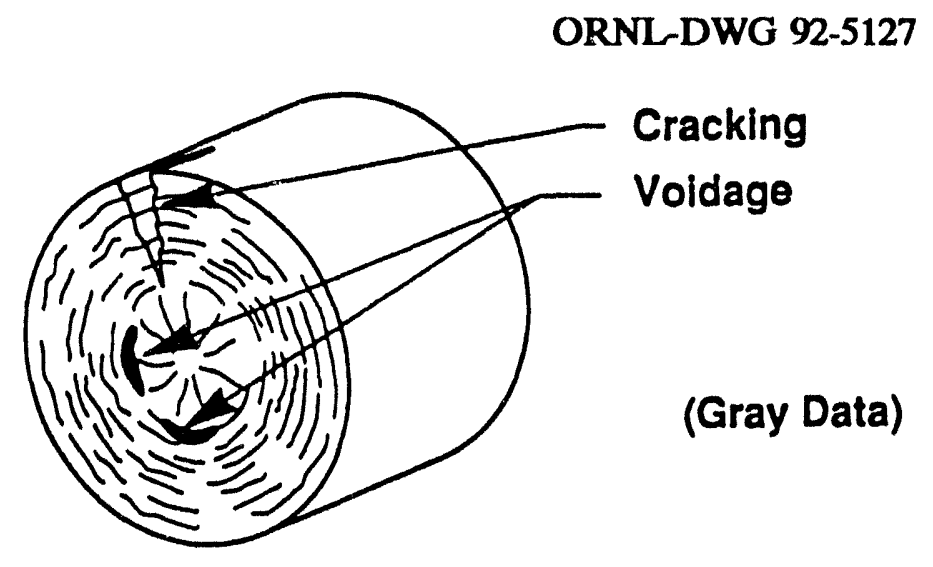

Fig. A2.3. Radiation damage in carbon fibers - fiber cracking.

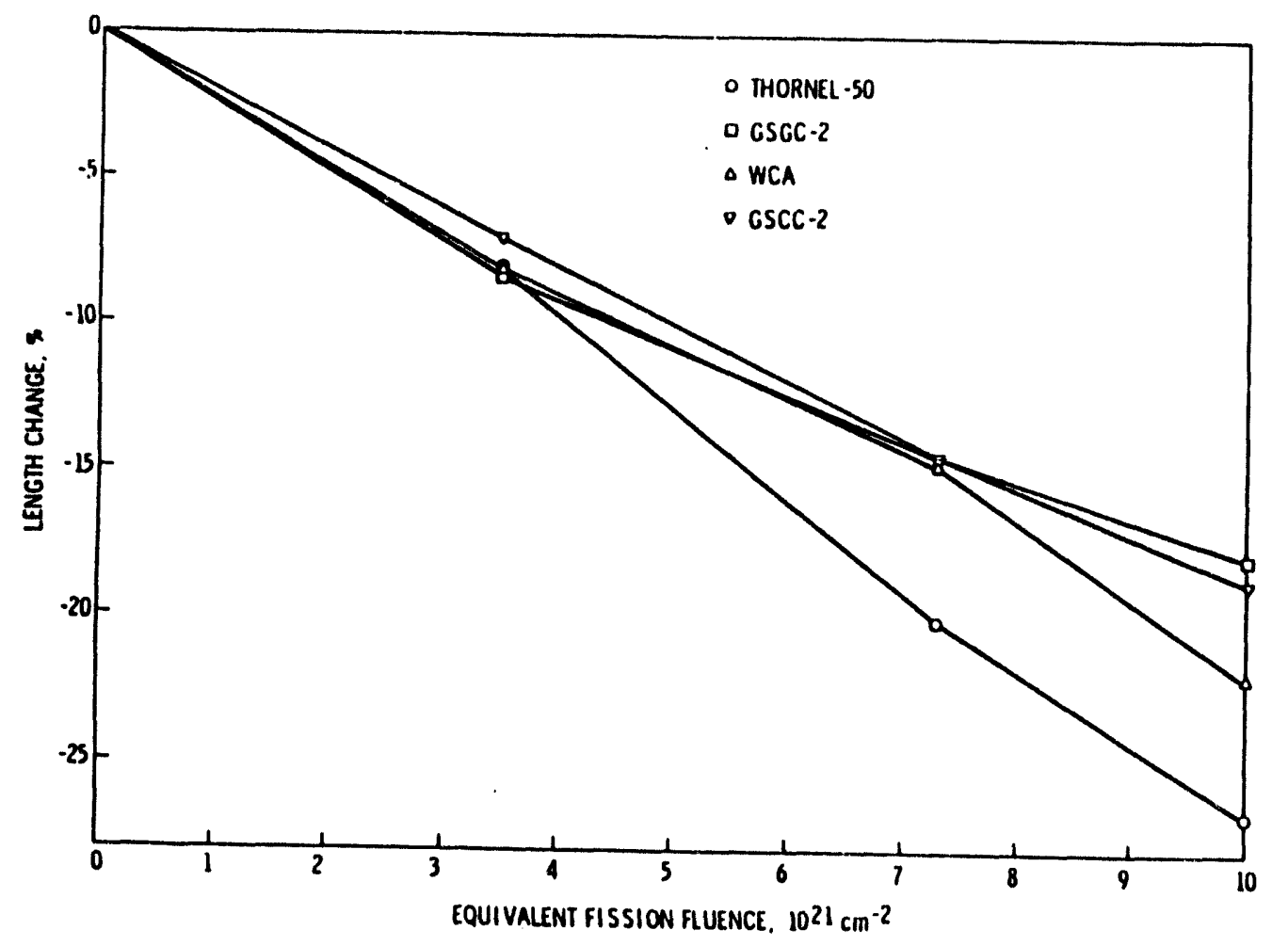

Fig. A2.4. Axial length changes of fibers in graphite and carbon cloths irradiated at $470^{\circ} \mathrm{C}$ (ref. 1). 
Table A2.1 Mean equivalent diameter changes of irradiated fibers ${ }^{1}$

\begin{tabular}{|c|c|c|c|}
\hline \multicolumn{2}{|c|}{ Fiber } & \multicolumn{2}{|c|}{ Diameter change $(\%)^{a}$} \\
\hline Number & Type & 3.5 by $10^{21} \mathrm{~cm}^{-1}$ & 10 by $10^{21} \mathrm{~cm}^{-2}$ \\
\hline 1 & $\begin{array}{l}\text { Thornel-50S } \\
\text { (WHY-140 1/2) }\end{array}$ & $-3.1 \pm 3.2$ & $+30.6 \pm 2.3$ \\
\hline 2 & GSGY-2 & $-5.5 \pm 2.4$ & $-3.6 \pm 3.6$ \\
\hline 3 & WYB-85 1/2 & $-0.4 \pm 2.4$ & $-6.7 \pm 6.6$ \\
\hline 4 & GSCY-2 & & $-6.8 \pm 1.9$ \\
\hline 5 & $\begin{array}{l}\text { Thornel-400 } \\
\text { (WYM-30 1/10) }\end{array}$ & & $-4.2 \pm 2.8$ \\
\hline 6 & Type A & $-5.5 \pm 2.3$ & $+0.3 \pm 3.2$ \\
\hline 7 & VSA-11 & & $+32.9 \pm 8.0$ \\
\hline 8 & $\begin{array}{l}\text { Thornel-75S } \\
\text { (WYJ-160 1/2) }\end{array}$ & & $-5.0^{b}$ \\
\hline 9 & C-20 & $-0.7 \pm 2.2$ & $-4.0 \pm 1.4$ \\
\hline 10 & $\begin{array}{l}\text { Thornel-300 } \\
\text { (WYP-30 1/0) }\end{array}$ & & $-15.8 \pm 2.9$ \\
\hline 11 & VBY-70 2/1) & & $-19.3 \pm 4.1$ \\
\hline
\end{tabular}

$a_{\text {Uncertainties listed are two times the standard deviations of the percentage }}$ difference between irradiated and unirradiated mean diameters. See text for discussion of additional uncertainties.

$b$ Only one irradiated fiber measured. 
ORNL-DWG 92-5128

- interstitials are stable at the botndaries

- probabilitity of anNTHILATION by Recorbination WITH VAGANCIES INGREASES WITH CRYSTALLITE SIZZ

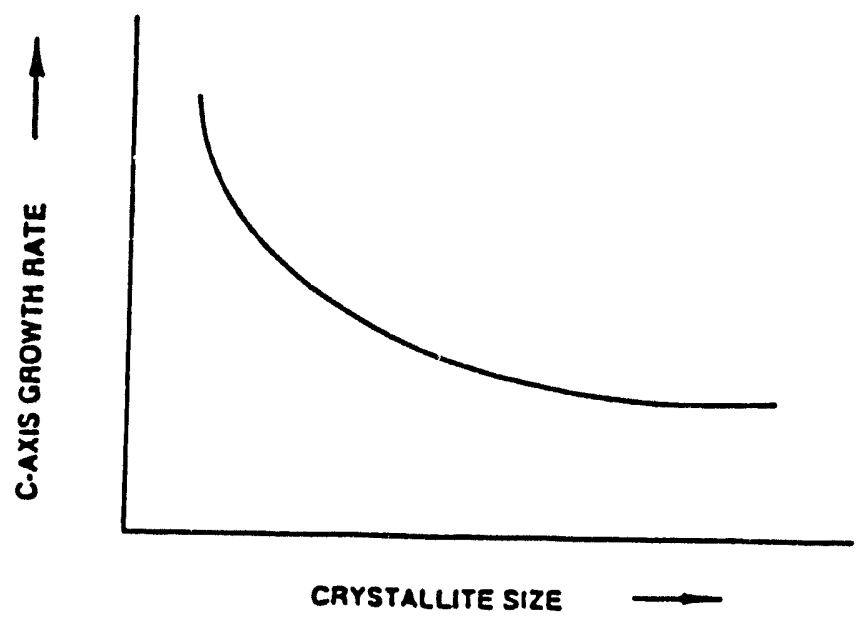

Fig. A2.5. The relationship between graphite crystallite size and c-axis growth rate.

created in large crystals have a higher probability of recombination with vacancies, compared to pinning at the crystallite boundary, than those created in smaller crystals. The crystallinity of carbon fibers increases with increasing heat-treatment temperature. For a given heat-treatment temperature, pitch fibers are more crystalline than PAN or rayon fibers. The effect of fiber crystallinity on radiation-induced fiber axial shrinkage has been demonstrated by Price et al. ${ }^{2}$ (Fig. A2.6), where the shrinkage was much less for pitch fiber than for PAN fiber. When carbon fibers/yarns are woven, the irradiation behavior of the cloth will be dominated by fiber axial shrinkage, and the internal voidage (between the warp and fill yarns) will be eliminated. This increases the crimp in the fabric, causing it to swell.

\section{A2.1.3 Radiation Damage in Carbon-Carbon Composites}

Little data exist on the behavior of these materials under neutron irradiation. ${ }^{1.5}$ However, recent data on irradiation-induced structural changes for a series of commercially available U.S. carbon-carbon composites have assisted our efforts to model radiation damage in these materials. The behavior of 2-D, carbon-carbon composites under neutron irradiation is shown in Fig. A2.7. Let us first consider a material where the fabric layers are parallel to the axis of the irradiation specimen (case 1 in Fig. A2.7). The fabric will shrink along its fiber/yarn axis, causing the 
ORNL-DWG 92-5125

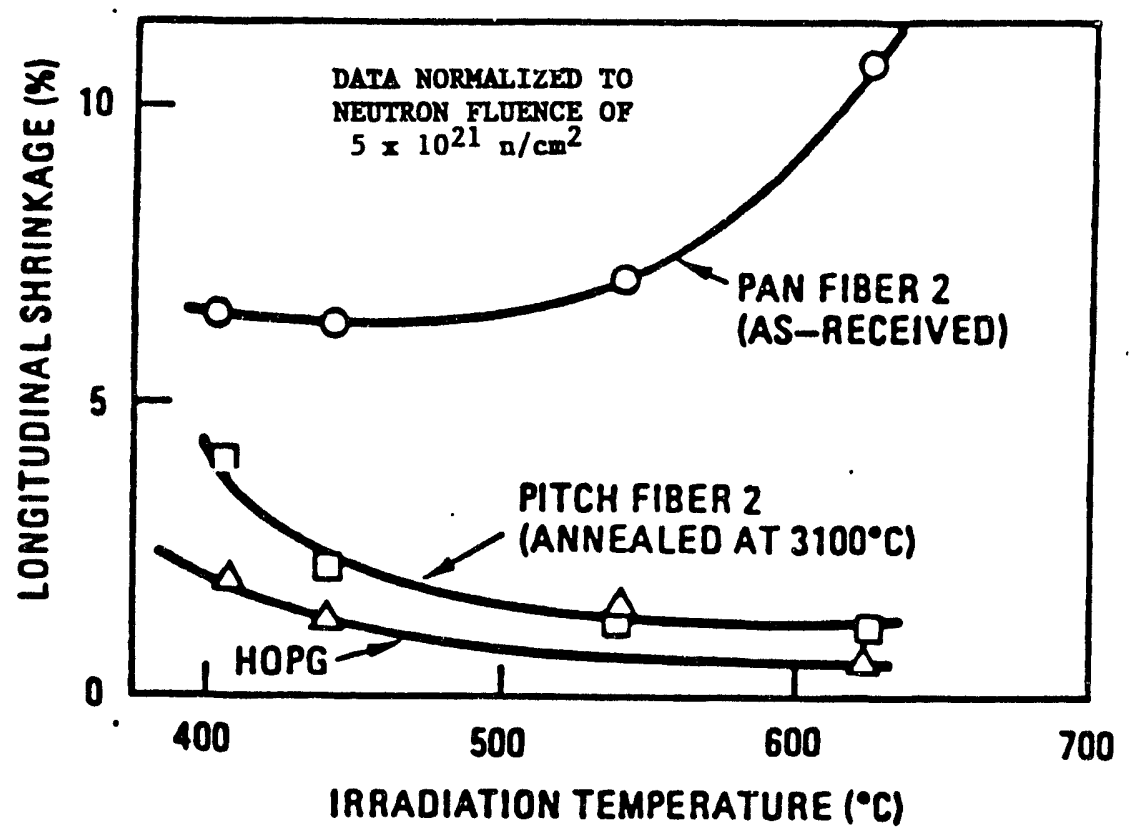

Fig. A2.6. Dependence of longitudinal shrinkage of carbon fibers on neutron-irradiation temperature. Note also the effect of high-temperature annealing to reduce shrinkage. ${ }^{2}$

ORNL-DWG 90M-11081

Parallel to cloth fiber shrinkage dominates.

\section{Case I.}

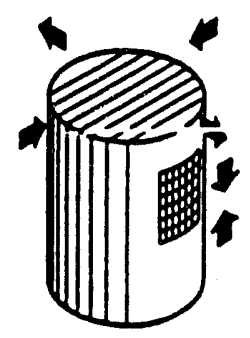

Cloth layers parallel to specimen axis (Mauny \& Couve.)
Case II.

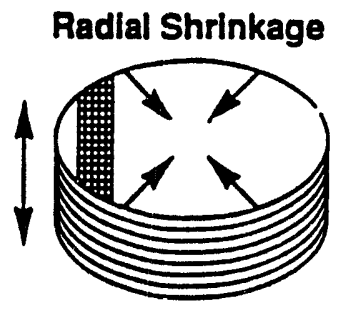

Cloth layers perpendicular to specimen axis (New data, Slagle \& Hollenburg.)

Fig. A2.7. Radiation damage in car'son-carbon composites. 
specimen to shrink axially and diametrally parallel to the cloth. The associated increase in the fabric crimp will cause a diametral expansion perpendicular to the cloth, resulting in an oval specimen cross section.

For case 2 shown in Fig. A2.7, we are modelling a 2-D, carbon-carbon composite in which the fabric layers are perpendicular to the axis of the irradiation specimen. This geometry is typical of many of the specimens irradiated in a MOTA during the recently completed cycle 10 of the FFTF. The specimens were irradiated at a temperature of approximately $400^{\circ} \mathrm{C}$ to a fluence of 10 to $12 \mathrm{dpa}(\mathrm{C})$. As in case 1 of Fig. A2.7, fiber axial shrinkage is the dominant effect, causing the specimens to shrink diametrally. If the weave is unbalanced (higher fiber content in either the warp or fill), the shrinkage may be nonuniform, resulting in ovality of the cross section. The diametral shrinkage will be accompanied by a crimp-related expansion in the specimen thickness.

A complete listing of the carbon-carbon composite specimens irradiated in the cycle 10 MOTA is given in Table A2.2. It is seen that these materials experienced axial dimensional changes ranging from $1 \%$ shrinkage to $84 \%$ growth. The diametral changes (estimated from photographs) ranged from +5.5 to $-18.8 \%$. The $2-\mathrm{D}, \mathrm{PAN}$ fiber, satin-weave samples (CC3 and CC4) both exhibited severe ovality. Estimates of the density changes have been made (Table A2.2). The specimen densities varied from a $27 \%$ decrease to a $26 \%$ increase. However, in comparing the dimensional and density changes reported, here the reader is cautioned that each material might be expected to first densify and then "turn around" and begin to swell. The rate of dimensional change will be heavily dependent on the material (and irradiation temperature), and thus direct comparison is complicated by the lack of data at other fluences for these materials. However, the following preliminary observations may be made:

1. For comparable architectures, the performance of pitch fibers appears to be superior to PAN fibers, e.g., specimen $\mathrm{CC} 1$ and $\mathrm{CC} 2 \mathrm{cf}$. specimens $\mathrm{CC} 3$ and $\mathrm{CC} 4$. This is not perhaps surprising given the known superior performance of pitch fibers cf. PAN fibers, ${ }^{5}$ which can be attributed to the greater degree of crystallinity exhibited by these fibers.

2. Composites with reinforcements between the fabric layers, such as 4-D (CC6 and CC7) or staple-knit (CC5) materials, exhibited significantly lower axial swelling than the 2-D materials. The diametral changes of these multidirectional materials are also smaller than those observed for the 2-D materials.

3. Specimen CC7 (4-D, fine-weave) exhibited superior behavior to specimen CC6 (4-D, coarse-weave). 


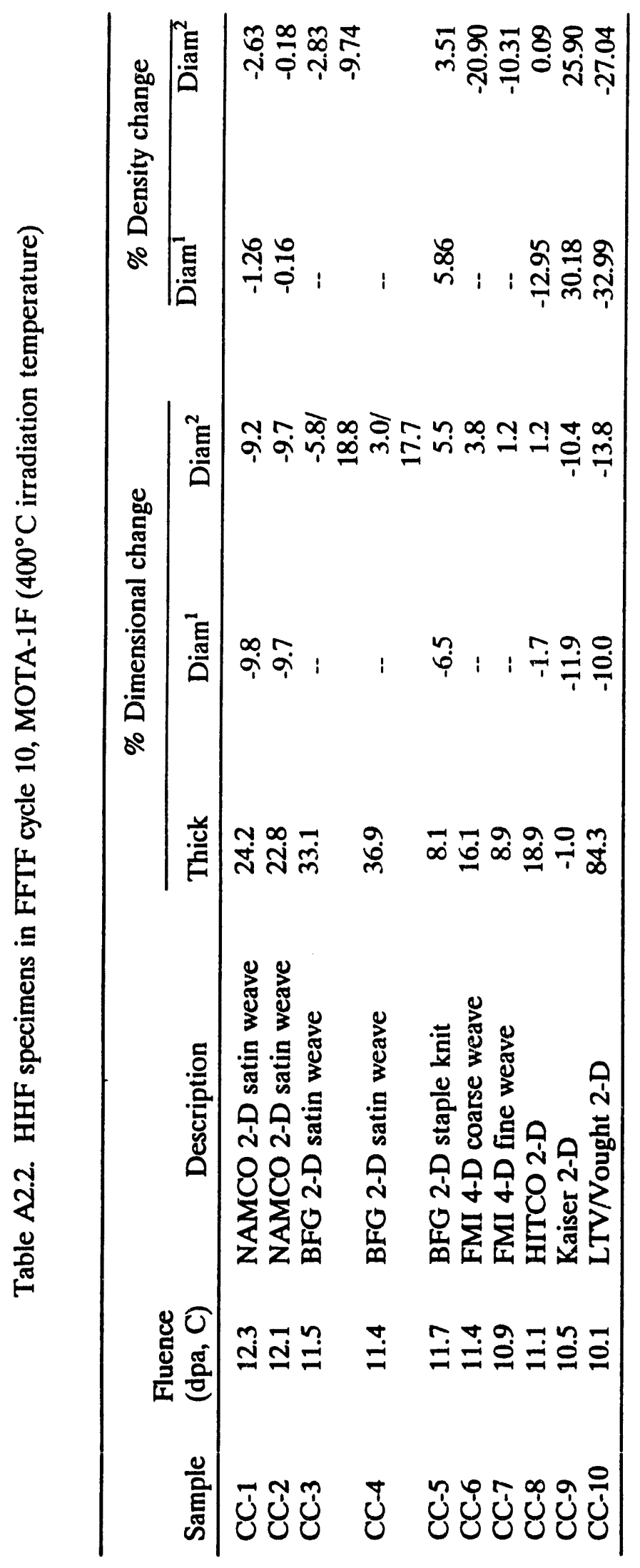




\section{A2.2 REFERENCES}

1. W. J. Gray, BNWL-2390, Battelle Pacific Northwest Laboratories, Richland, Wash., 1970.

2. R. J. Price, R. J. Hopkins, and G. B. Engle, p. 340 in Proceedings of 17 th Biennial Conference on Carbon, 1985.

3. P. Mauney and D. Couve, CEA Report (in French), 1984.

4. I. D. Peggs and R. W. Mills, p. 188 in Proceedings of 10th Annual Conference on Carbon, 1971.

5. B. F. Jones, ibid, p. 190. 
ORNL/TM-12047

Distribution

Category UC-424

\section{INTERNAL DISTRIBUTION}

1-2. Central Research Library

3. Document Reference Section

4-5. Laboratory Records Department

6. Laboratory Records, ORNL RC

7. ORNL Patent Section

8-10. M\&C Records Office

11. D. J. Alexander

12. R. L. Beatty

13. T. M. Besmann

14. P. J. Blau

15-19. T. D. Burchell

20. D. R. Childress

21. R. E. Clausing

22. R. H. Cooper

23. D. F. Craig

24-29. W. P. Eatherly

30. E. L. Fuller, Jr.

31. M. L. Grossbeck

32. H. Haselton

33. C. Hsueh

34. M. G. Jenkins

35. O. F. Kimball

36. R. L. Kleuh

37. E. A. Kenik
39. R. A. Lowden

40. G. M. Ludtka

41. J. R. Mayotte

42. B. F. Myers

43. T. A. Nolan

44. A. E. Pasto

45. J. E. Pawel

46. M. Peug

47. P. L. Rittenhouse

48. M. J. Saltmarsh

49. J. Sheffield

50. J. P. Strizak

51. P. T. Thornton

52. D. F. Wilson

53. C. E. Weaver

54. A. A. Wereszcak

55. S. J. Zinkle

56. Y. A. Chang (Consultant)

57. H. W. Foglesong (Consultant)

58. J. J. Hren (Consultant)

59. M. L. Savitz (Consultant)

60. J. G. Simon (Consultant)

61. K. E. Spear (Consultant)

\section{EXTERNAL DISTRIBUTION}

62. APPLIED SCIENCES, INC., P.O. Box 186, Yellow Springs, OH 45387-0186 M. Lake

63-65. ARGONNE NATIONAL LABORATORY, 9700 South Cass Avenue, Argonne, IL 60439
J. Brooks
R. F. Mattas
D. W. Smith 
66-72. BATTELLE PACIFIC NORTHWEST LABORATORIES, P.O. Box 999, Richland, WA 99352

G. W. Hollenberg (5)

D. Slagle

J. Youngblood

73-74. GENERAL ATOMICS, INC., P.O. Box 85608, San Diego, CA 92186-9784

C. B. Baxi, MS 13-169

K. R. Schultz, MS 13-166

75. IDAHO NATIONAL ENGINEERING LABORATORY, P.O. Box 1625, Idaho Falls, ID 83415

D. Holland

76-78. McDONNELL DOUGLAS MISSILE SYSTEMS, P.O. Box 516, Code 092 2242, St. Louis, MO 63166-0516

D. A. Bowers

J. W. Davis

J. W. Sapp

79-83. NAMCO, Inc., 16716 Martincoit Road, Poway, CA 92064

G. B. Engle (5)

84-86. PRINCETON UNIVERSITY, Plasma Physics Laboratory, James Forrestal Campus, P.O. Box 451, Princeton, NJ 08544
S. Cohen
D. Post
M. A. Ulrickson

87-89. SANDIA NATIONAL LABORATORIES, Fusion Technology, Division 6514, P.O. Box 5800, Albuquerque, NM 87185

W. Gauster

R. T. McGrath

J. B. Whitley

90-91. SANDIA NATIONAL LABORATORIES, P.O. Box 969, Livermore, CA 94550-0096
R. A. Causey
K. L. Wilson 
92-93. UNIVERSITY OF CALIFORNIA AT LOS ANGELES, Institute of Plasma and Fusion Research, 6291 Boelter Hall, 405 Hilgard Avenue, Los Angeles,

CA $90024-8534$

R. W. Conn

Y. Hirooka

94. UNIVERSITY OF TORONTO, Institute for Aerospace Studies, 4925 Dufferin Street, Downsview, Ontario, Canada M3H-5T6

Prof. A. A. Haasz

95-100. DOE, OFFICE OF FUSION ENERGY, ER-51 GTN, Washington, DC 20585 M. M. Cohen

N. A. Davis

R. J. Dowling

G. R. Nardella

R. E. Price

F. W. Wiffen

101. DOE OAK RIDGE FIELD OFFICE, Oak Ridge, TN 37831-6269

Office of Assistant Manager for Energy Research and Development

102-141. DOE, OFFICE OF SCIENTIFIC AND TECHNICAL INFORMATION, P.O. Box 62, Oak Ridge, TN 37831

Given distribution as shown in DOE/OSTI-4500, Distribution Category UC-424 (Magnetic Fusion Energy Systems) 

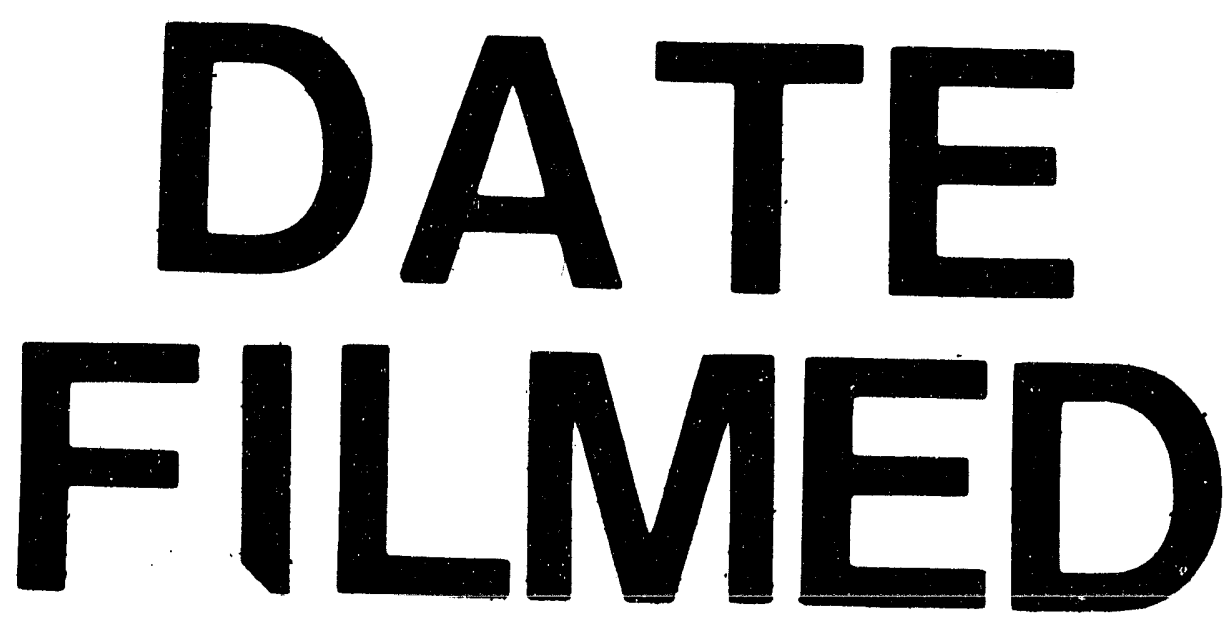

$01 / 20 / 93$ 


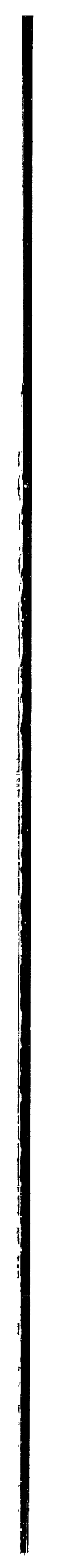

